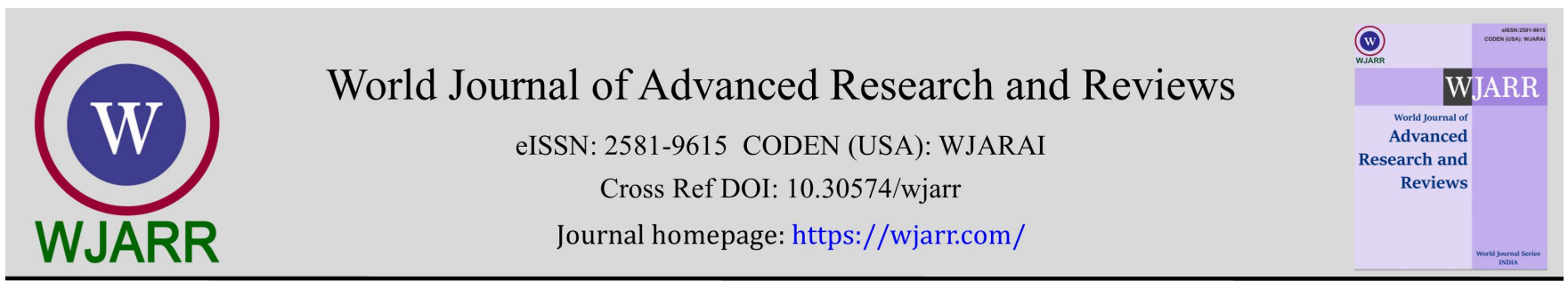

(RESEARCH ARTiClE)

\title{
Thermal behavior and thermodynamic parameters of some complexes of biologically active nucleic acid constituents
}

\author{
M. S. Masoud ${ }^{1,}{ }^{*}$, M. Sh. Ramadan ${ }^{1}$, A. M. Sweyllam ${ }^{2}$, A. M. Ramadan ${ }^{1}$ and M. H. Al-Saify ${ }^{3}$ \\ ${ }^{1}$ Chemistry Department, Faculty of Science, Alexandria University, Alexandria, Egypt. \\ ${ }^{2}$ Physics Department, Faculty of Science, Alexandria University, Alexandria, Egypt. \\ ${ }^{3}$ Sidi Kerir Petrochemicals Company, Alexandria, Egypt.
}

World Journal of Advanced Research and Reviews, 2021, 12(02), 078-108

Publication history: Received on 22 September 2021; revised on 29 October 2021; accepted on 31 October 2021

Article DOI: https://doi.org/10.30574/wjarr.2021.12.2.0556

\begin{abstract}
The thermal behavior of some complexes derived from biologically nucleic acid constituents has been studied applying differential scanning calorimetry (DSC) and thermogravimetric analysis (TGA) techniques. Thermodynamic parameters, decompositions and thermal stabilities are calculated and explained. All the complexes gave exothermic peaks with -ve signs for change of entropy values, $\Delta \mathrm{S}$ which indicate that the activated transition states are more ordered, i.e. in a less random molecular configuration than the reacting complexes. TGA gives the mechanism of decomposition.
\end{abstract}

Keywords: Ligands; Complexes; DSC; Debye Model; Thermodynamic Parameters; Fragmentation Pathways

\section{Introduction}

Possibilities for research in the coming decade with new techniques, which follow the reactions of Pt complexes and nucleic acids and proteins, will allow the detection of otherwise invisible intermediate products. The need for new platinum antitumor drugs was underscored by the usefulness of cisplatin and carboplatin in chemotherapy and the resistance of many tumors to these compounds. Combinatorial chemistry could aid in the search for cisplatin analogs if fast, high-throughput assays were available. The goal is to develop rapid cell-based assays suitable for high-throughput screening that accurately predicts the cytotoxicity of platinum complexes. The next stage in drug design is likely to be the development of dedicated drugs that comprise the transport (through the membranes), survival in the cell, binding to the DNA, and eventually, excretion from the body with minimum side effects. In this process, both metal coordination and hydrogen bonding will be key factors at the molecular level. Recent advances in medicinal inorganic chemistry demonstrate significant prospects for the utilization of metal complexes as drugs, presenting a flourishing arena for inorganic chemistry. Significant progress in platinum based anticancer agents has been achieved, based in part on a mechanistic understanding of the DNA-binding and pharmacological effects of cisplatin.

DNAs are the target molecules for most of the metal anticancer agents in human body. The anticancer nature is the coordination of metal ions with DNA molecules. i.e. the direct chelation of the metal ions with certain nucleophilic groups in DNA (such as oxygen sites from phosphates and nitrogen as well as oxygen sites from bases), causing the DNAs' damage in cancer cells, the DNAs were hindered during the processes of replication or transcription, the growing and division of the cancer cells were stopped, and resulted in their death.

\footnotetext{
${ }^{*}$ Corresponding author: M. S. Masoud

Chemistry Department, Faculty of Science, Alexandria University, Alexandria, Egypt.

Copyright $@ 2021$ Author (s) retain the copyright of this article. This article is published under the terms of the Creative Commons Attribution Liscense 4.0.
} 
When drug molecules (pre-anticancer molecules) enter into an organism, they will first undergo a series of processes including hydrolysis, transport and membrane-crossing, and then reach the nearby of the target DNA molecule and form active intermediates which interact with DNA molecules directly and exert the anticancer activity. These active intermediates have a general cis-form of two-water-binding transitional state:

$$
\left[\text { cis- } \mathrm{A}_{\mathrm{n}} \mathrm{M}\left(\mathrm{H}_{2} \mathrm{O}\right)_{2}\right]^{\mathrm{m}+} \text {, }
$$

where $\mathrm{A}$ is stably binding hydrophobic group, $\mathrm{n}=1,2$ or more and $\mathrm{M}$ is metal ion.

The number of water molecules binding to M must not be fewer than two and they must be lie in the ortho-position of the structure.

The functions of the hydrophobic ligand A are:

- $\quad$ caring the whole molecule to cross membranes (including cell membranes and nucleus membranes), go through the bilipid bilayers.

- making the metal ion to move to the nearby of the base's cyclic-nitrogen sites and form covalent bonding.

Metal anticancer complexes are often electrophilic and may react with many cellular components, such as simple ions and molecules like $\mathrm{Cl}^{-},\left(\mathrm{HPO}_{4}\right)^{2-}, \mathrm{OH}^{-}$and $\mathrm{H}_{2} \mathrm{O}$; amino acids , peptides and polyphosphates like histidine (His), methionine (Met), cysteine (Cys), glutathione, metallothionein and ATP. From the view of the coordination chemistry, metal complexes (including those of Pt0 can bind to several types of possible biomolecules in the cell. But only the binding on DNA which lead to cell death is considered the most important. In the case of platinum complexes, it is quite clear that in the cells, after the relatively slow hydrolysis, cis-Pt have a preference for DNA over proteins and other molecules. Lmethionine increases the rate of reaction of 5'-GMP with cisplatin and that S-bound L-HMet in the adduct [Pt (dien) (LHMet-S $)]^{2+}($ dien= 1, 5-diamino-3-azapentane 0 can be replaced by N7 of 5'GMP [1, 2]. A methionine-containing protein or peptide could transport and transfer some platinum to DNA [2].

Thus, in a very simple model, the action process of a metal anticancer agent in an organism may be briefly summarized into following equations:

$\left.\left.\mathrm{DX}_{2}+2 \mathrm{H}_{2} \mathrm{O} \rightleftharpoons{ }_{2}\right)_{2}\right]^{2+}+2 \mathrm{X}^{-}$

$\left.\left.\left[\mathrm{D}\left(\mathrm{H}_{2} \mathrm{O}\right)_{2}\right]^{2+}+\mathrm{DN} t=\right)\right]^{2+}+2 \mathrm{H}_{2} \mathrm{O}$

$\mathrm{DX}_{2}$ is the pre-anticancer molecule,

$\left[\mathrm{D}\left(\mathrm{H}_{2} \mathrm{O}\right)_{2}\right]^{2+}$ is the active intermediate produced by hydrolysis,

DNA-D is DNA-drug complex.

DNA molecule is a two-pole molecule, its surface is a negatively-charged backbone of phosphatepentose chains. In the inside of double helix there exist hydrophobic bases stacking layer by layer. For exerting its potency, the drug molecules must build with the phosphate groups of DNA at first, and then, with the help of DNA' conformational dynamic changes (partial unwinding of the double helix), the lipophilic groups of the drug molecule may be drawn by DNA's hydrophobic sections, the nitrogen sites on DNA molecules may be exposed, the metal atom could invade into the internal part of DNA and coordinates with the bases. Oxygen site on the phosphate group has a higher negative charge relatively, it is a good donor with high electronegativity; so its action with the metal atom was caused mainly by static electricity, forming electrovalency, belongs to charge-controlling reaction.

Through the study on hydrolysis mechanism and relationship between structure and activity of metal anticancer agents, the following three points are key if the metal anticancer agents have activities:

Appropriate hydrolysis rates of a complex.

Forming the active intermediate $\left[\text { cis- } \mathrm{A}_{n} \mathrm{M}\left(\mathrm{H}_{2} \mathrm{O}\right)_{2}\right]^{\mathrm{m}+}$.

(3) Forming of the coordination both with the oxygen of phosphate groups and with nitrogen of bases. 
The molecules with high anticancer activities should not only produce active intermediates by the proper hydrolysis rates, but also bind to both oxygen of phosphate groups and nitrogen of base in DNA, thus showing anticancer activity.

The two pole complementary principle (TPCP) has generalized the molecular structure, action modes and steric selectivity for metal anticancer agents. TPCP includes three aspects:

\subsection{Two-pole complement in molecular structures}

The drug molecules with anticancer activity always have two poles of hydrophilicity and hydrophobicity, positive and negative charges in their structures. Correspondingly, they will present easily-leaving groups and stable keeping groups in a solution. Such two-pole structures can lead the drug molecules not only to be dissolved in water and transported to the surface of the cell membranes, but also to cross the membranes by going through the lipid bilayers and arrive at the nearby of the target molecules.

\subsection{Two-pole complement in the receptor-substrate action mode}

The interaction between the drug molecule and its target molecule is always executed by forming an active intermediate which binds with oxygen sites (electrovalently) on phosphate groups and nitrogen sites (covalently) on purines, pyrimidines of DNA backbone through charge-controlling and orbital-controlling. That is a two-pole complement of electrovalent and covalent action modes.

\subsection{Two-pole complement in the symmetry of the receptor-substrate system}

The interaction characteristics of a chiral drug molecule with DNA behave as using the left hand enantiomer of the drug molecule binding with the right hand DNA, forming a two-pole complementary complex chirally.

\section{Experimental}

\subsection{A- Synthesis of metal complexes in the solid state}

These were prepared by mixing metal chloride and acetylacetonate (acac) solutions with ligand solutions, Table (1), hence they were refluxed, filtered and dried for the separated products. The metal ions were determined by atomic absorption techniques and complexometric titrations using published procedures [3]. The complexes were digested by aqua regia several times to complete decomposition for the organic ligand compounds.

\subsection{B- Instruments and working procedures}

\subsubsection{Thermal analysis}

The samples were measured using (TGA-50H detector, platinum cell, nitrogen atmosphere, $20 \mathrm{ml} / \mathrm{min}$ flow rate) and (DSC-60A detector, aluminum cell, nitrogen atmosphere, $50 \mathrm{ml} / \mathrm{min}$ flow rate).

Table 1 Names, abbreviations, m.p. and structures of the ligands are given

\begin{tabular}{|l|l|l|l|}
\hline Compound & Abbreviation & M.P. ${ }^{\circ} \mathbf{C}$ & Structures \\
\hline Adenine & (AD) & $360-365$ & \\
& & &
\end{tabular}




\begin{tabular}{|c|c|c|c|}
\hline 9-Hydroxyethyladenine & (HEAD) & 244 & $\mathrm{NH}_{2}$ \\
\hline 6-Acetyladenine & (ACAD) & $216-217$ & \\
\hline Barbituric acid & $(\mathrm{BA})$ & 248 & $\mathrm{O}$ \\
\hline Thiobarbituric acid & $(\mathrm{TBA})$ & 245 & O \\
\hline 2-Thiouracil & (TU) & 340 & $\mathrm{O}$ \\
\hline
\end{tabular}

\section{Thermal analysis}

Thermal analysis plays an important role in studying the structure and the properties of metal complexes in the solid state. A number of solid state reactions (e.g., thermal isomerization, conformational changes, polymorphic transformations, thermal phase transitions, thermochromism, etc...) can be explained using thermal analysis [4-14].

The thermal behavior of some complexes has been studied applying differential scanning calorimetry (DSC), Figures (110) and Thermogravimetric analysis (TGA) techniques. Thermodynamic parameters, decompositions and thermal stabilities are calculated and explained, Figures ( (11 (a, b)-20 (a, b)), (21-27)), Tables $(2,3)$ which can be correlated with their structures [14-19]. It's known that, in general, different polymorphs of some compounds exist as different structures and possess variable properties, e.g. density, hardness, crystal shape, optical and electrical properties, etc..). The compounds probably occur with different structures [20]. Some crystalline matter display the phenomenon of polymorphism which are crystal solvates containing solvents of crystallization. The nature of the interaction of the solvent with the host molecule can be used for explaining the behaviour of solvates [13]. Crystal solvates display polymorphic and pseudo-polymorphic transformations upon desolvation according to the nature of interaction [21].

DSC measurements are considered to be applied from both qualitative and quantitative views and provide information about physical and chemical changes involving endothermic, exothermic processes and changes in heat capacity. 
DSC plot is used to determine the melting temperature through melting transition, where, the complex should absorb heat until all the crystals have melted, Table (2).

The Debye model [22]is used to describe capacity change over a large temperature range and $\mathrm{C}_{\mathrm{p}}$ can be represented by the following empirical form: $\mathrm{C}_{\mathrm{p}}=\mathrm{aT}+\mathrm{b}$.

By plotting $C_{p}$ versus $T$, a straight line is obtained, where a and $b$ are parameters which can be determined from the slope and intercept of the line, respectively, Figures (11a-20a), Table (2).

The applications based on Debye model for selected complexes are given from the following equations [23]:

$\mathrm{C}_{\mathrm{p}} \simeq \mathrm{C}_{\mathrm{v}}=\alpha \mathrm{T}^{3}+\gamma \mathrm{T}, \quad \frac{\mathrm{Cp}}{T}=\alpha \mathrm{T}^{2}+\gamma$

where $\alpha$ and $\gamma$ are the coefficients of the lattice and electronic heat capacities, respectively. $C_{V}$ is the heat capacity at constant volume which is assumed to be equal to $\mathrm{C}_{\mathrm{p}}$.

The relationships of $\frac{\mathrm{Cp}}{T}$ versus $\mathrm{T}^{2}$ give straight lines with slopes $\alpha$ and intercepts $\gamma$, Figures (11b-20b), Table (2).

The straight lines are analyzed and the validity is calculated with $R^{2}$ values for each line, Figures (11 (a, b)-20 (a, b)).

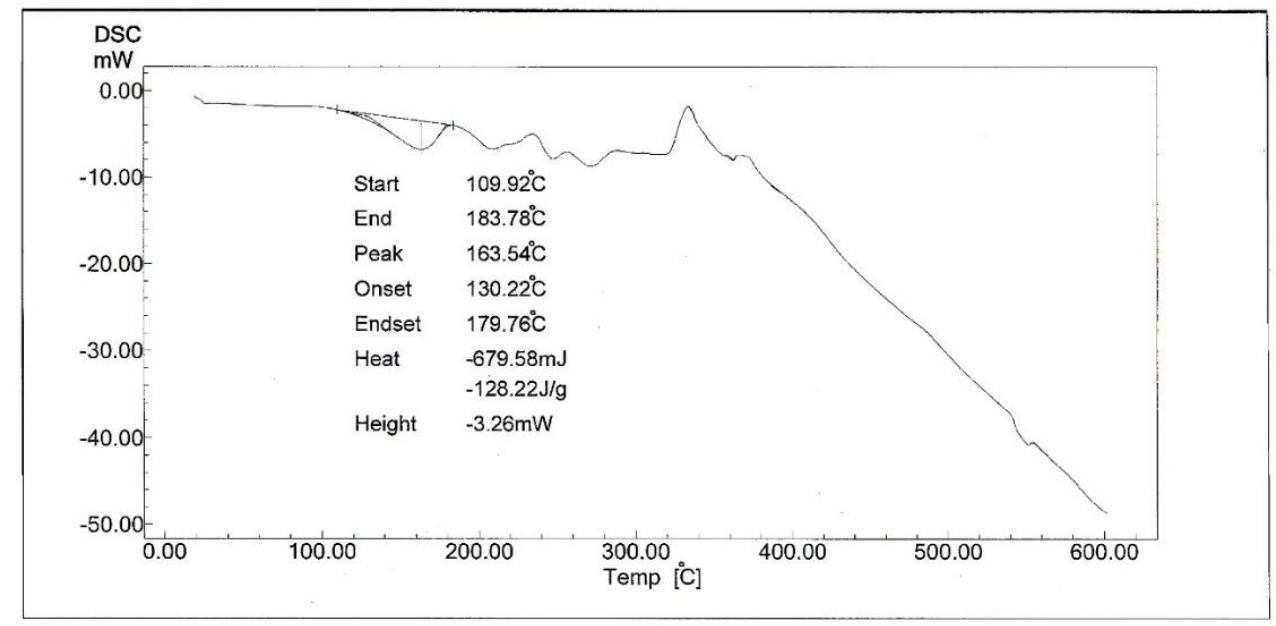

Figure 1 DSC for Fe (adenine) 3 .

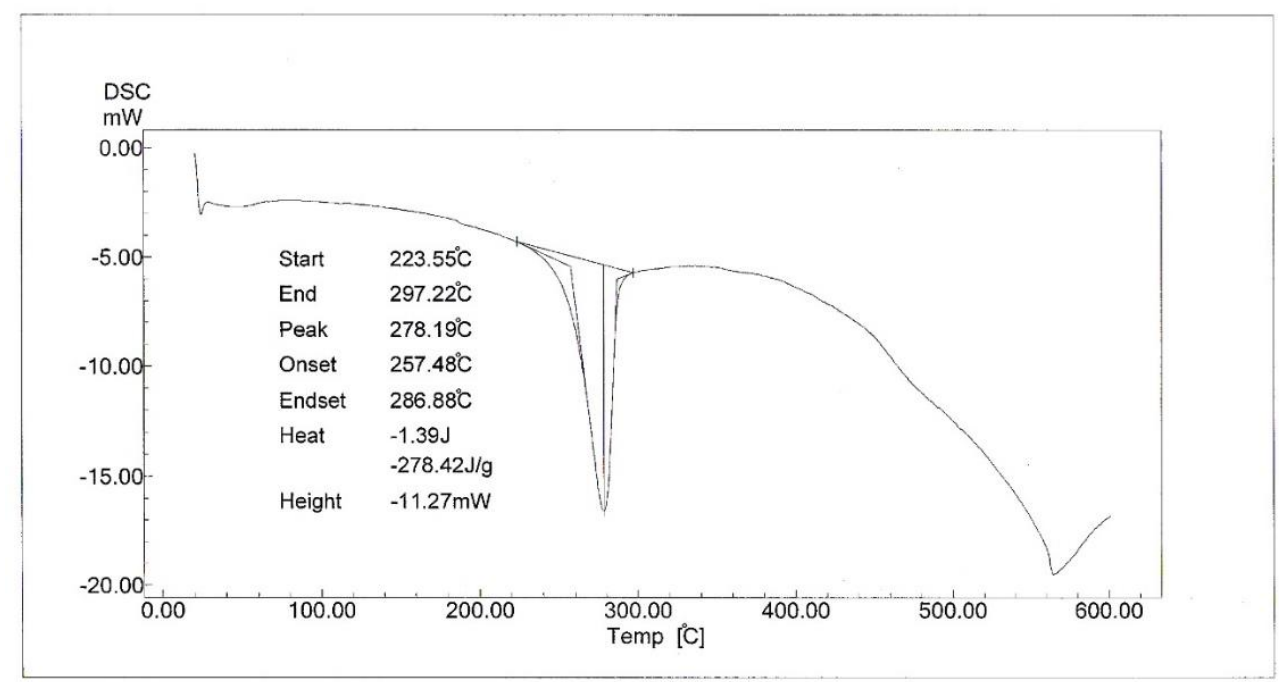


World Journal of Advanced Research and Reviews, 2021, 12(02), 078-108

Figure 2 DSC for Co (acac) 2 (adenine).

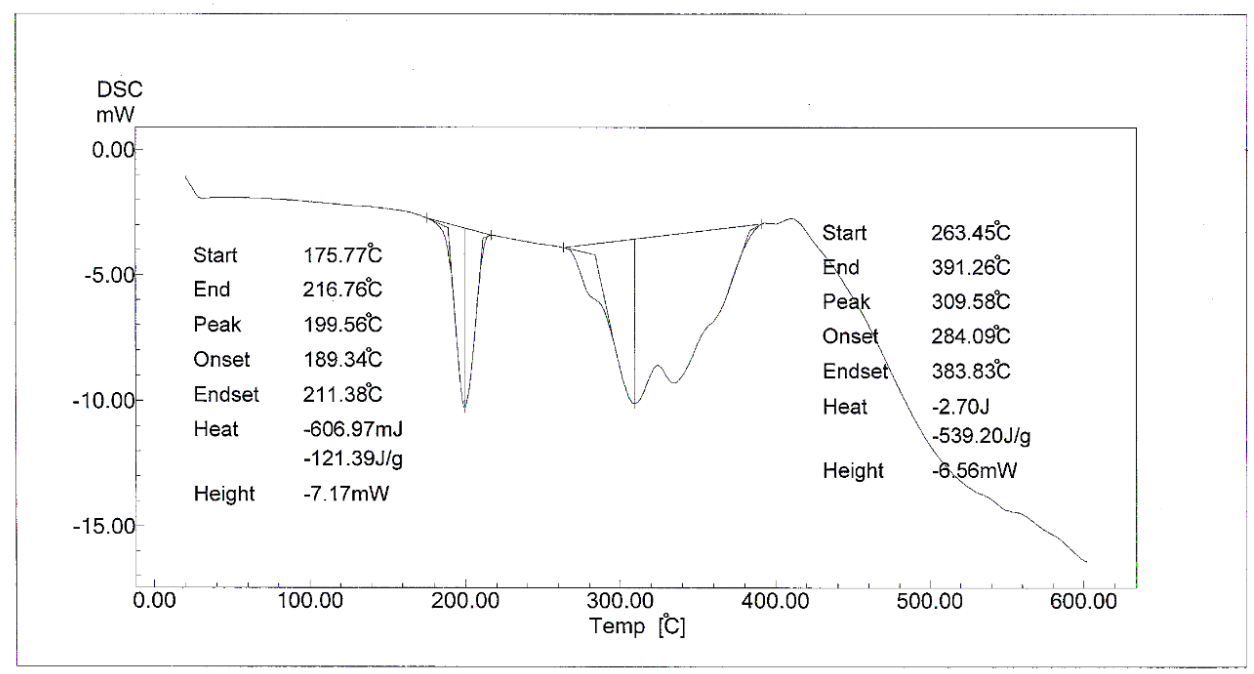

Figure 3 DSC for Zn (hydroxyethyladenine) $)_{2}\left(\mathrm{OH}^{-}\right)_{2} \cdot 2 \mathrm{H}_{2} \mathrm{O}$.

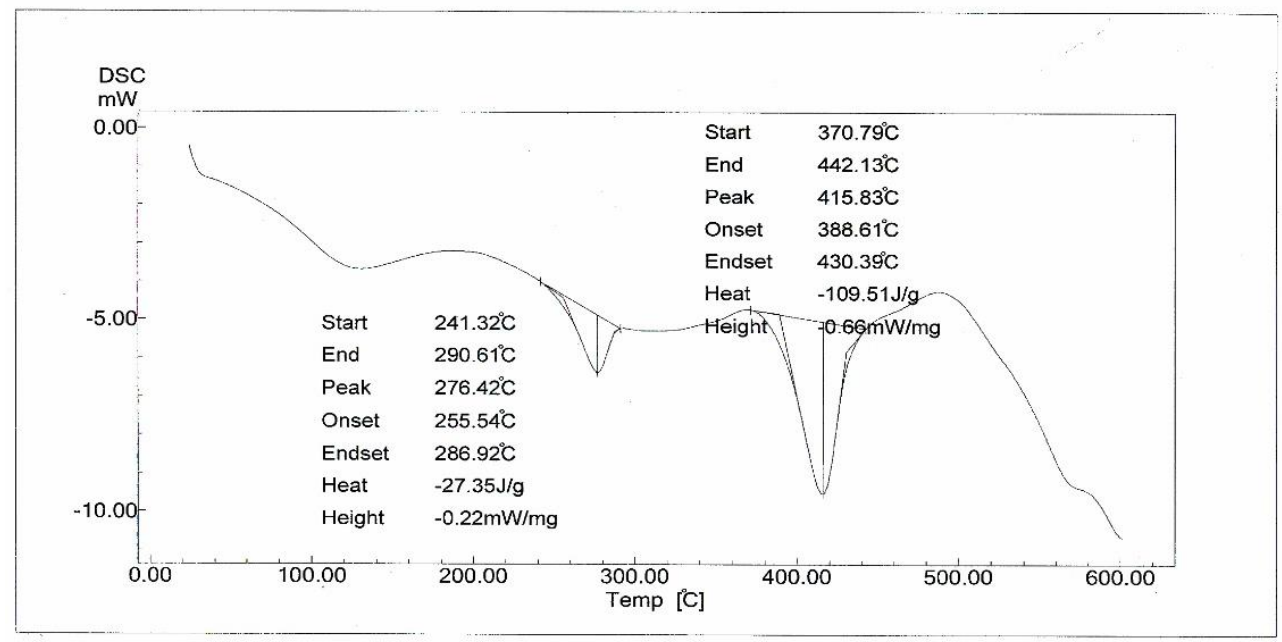

Figure 4 DSC for $\mathrm{Cr}(\mathrm{BA})\left(\mathrm{OH}^{-}\right) \cdot 4 \mathrm{H}_{2} \mathrm{O}$.

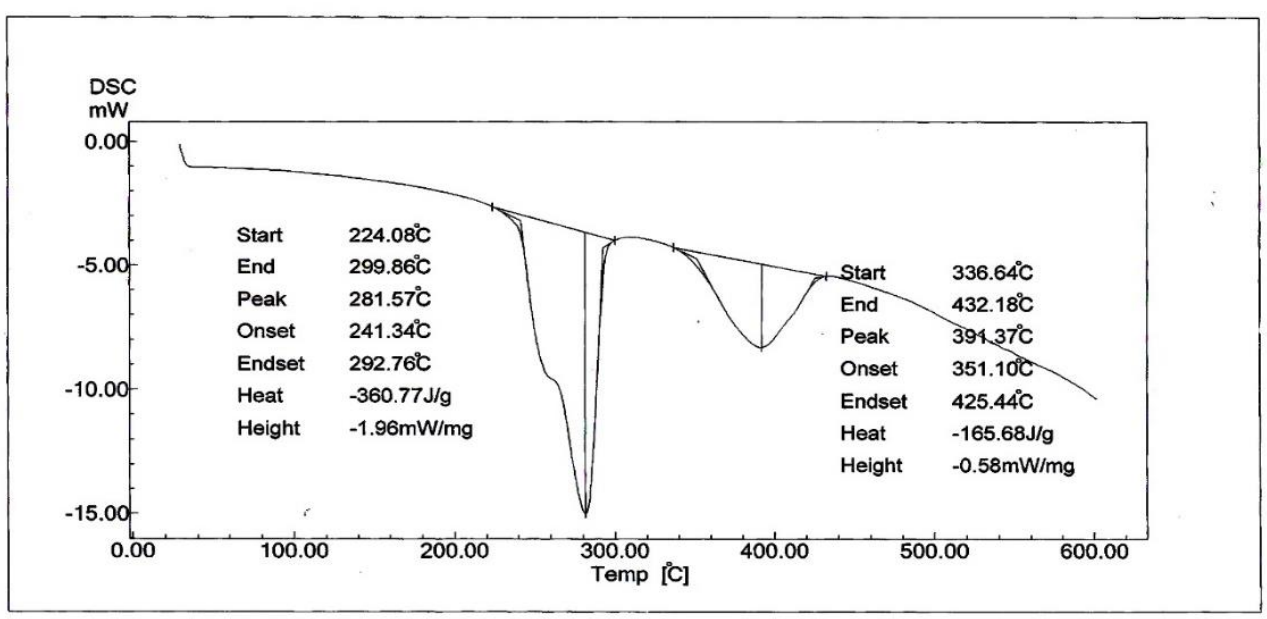


World Journal of Advanced Research and Reviews, 2021, 12(02), 078-108

Figure $5 \mathrm{DSC}$ for $\mathrm{Zn}(\mathrm{BA})_{2} .3 \mathrm{H}_{2} \mathrm{O}$.

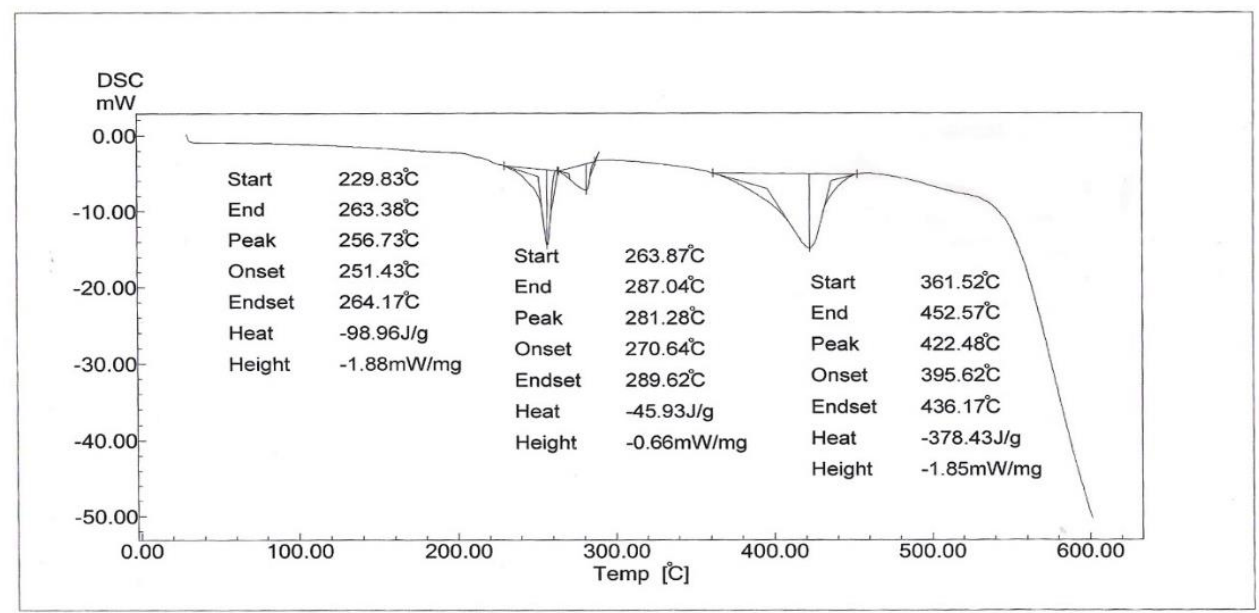

Figure 6 DSC for $\mathrm{Cd}(\mathrm{BA})_{2} \cdot 10 \mathrm{H}_{2} \mathrm{O}$.

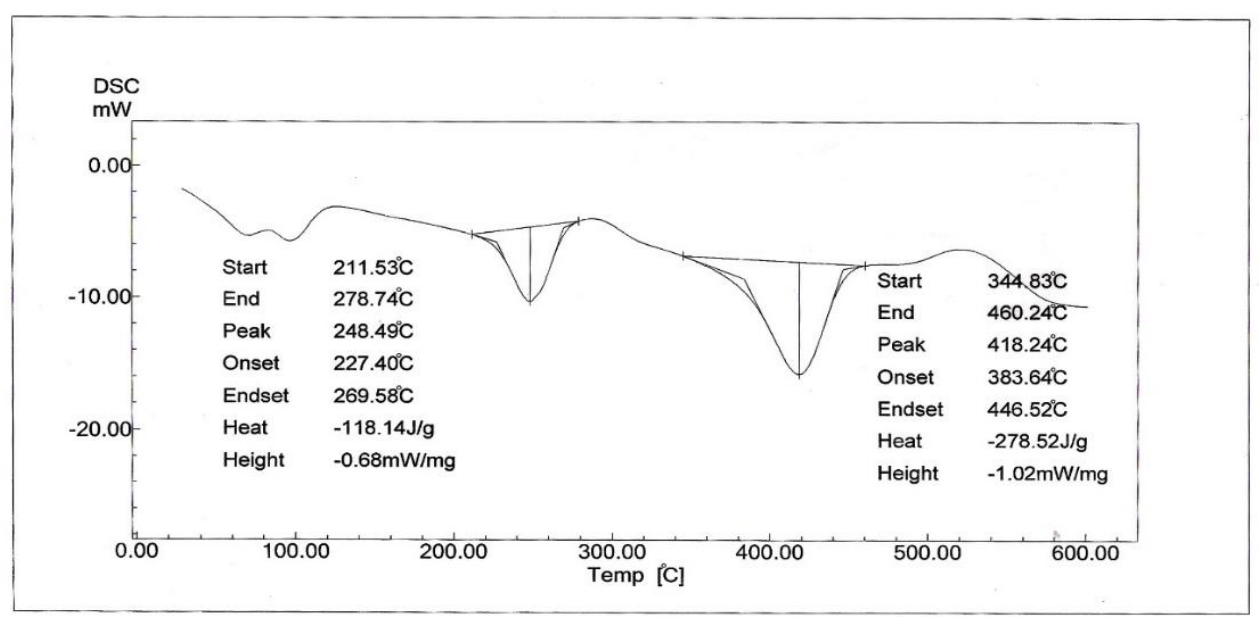

Figure 7 DSC for $\mathrm{Hg}(\mathrm{BA})_{2}$.

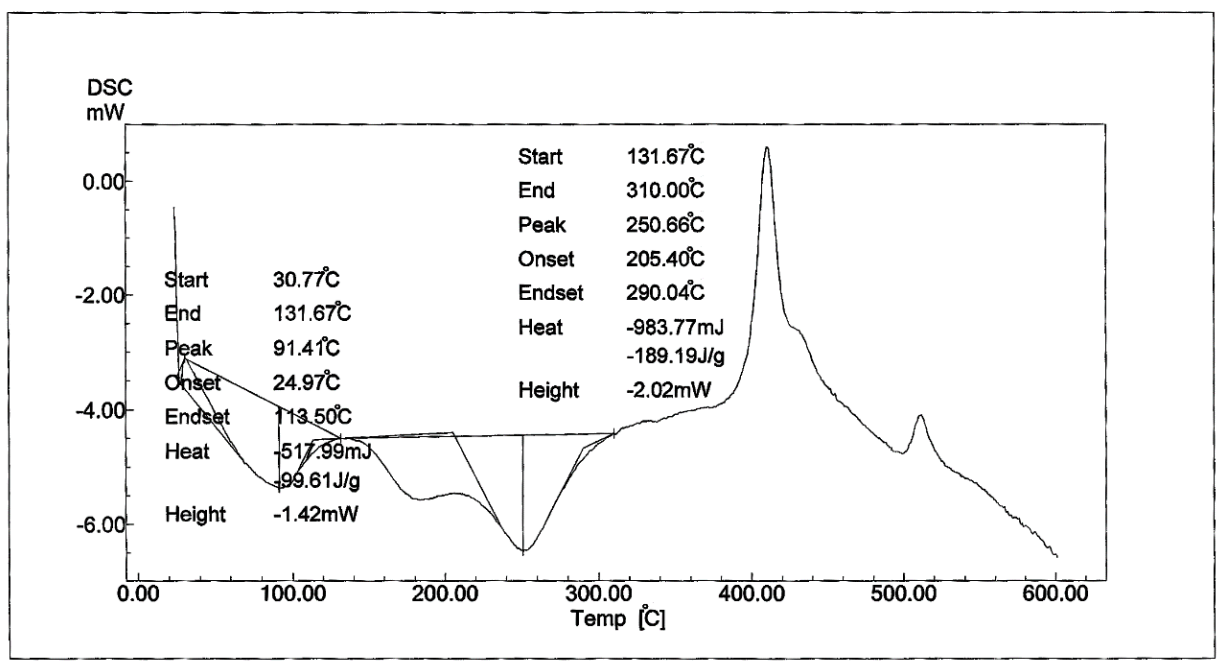


Figure 8 DSC for Fe (TBA) $\left(\mathrm{OH}^{-}\right) .2 \mathrm{H}_{2} \mathrm{O}$.

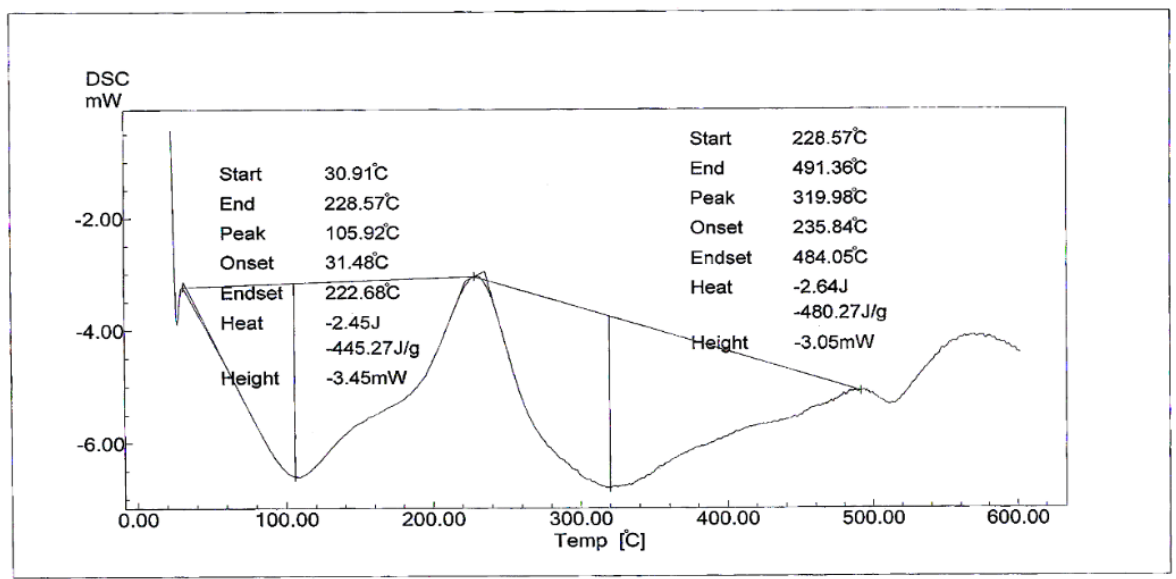

Figure 9 DSC for $\mathrm{Cr}(\mathrm{TU})\left(\mathrm{OH}^{-}\right)_{2} \cdot \mathrm{H}_{2} \mathrm{O}$.

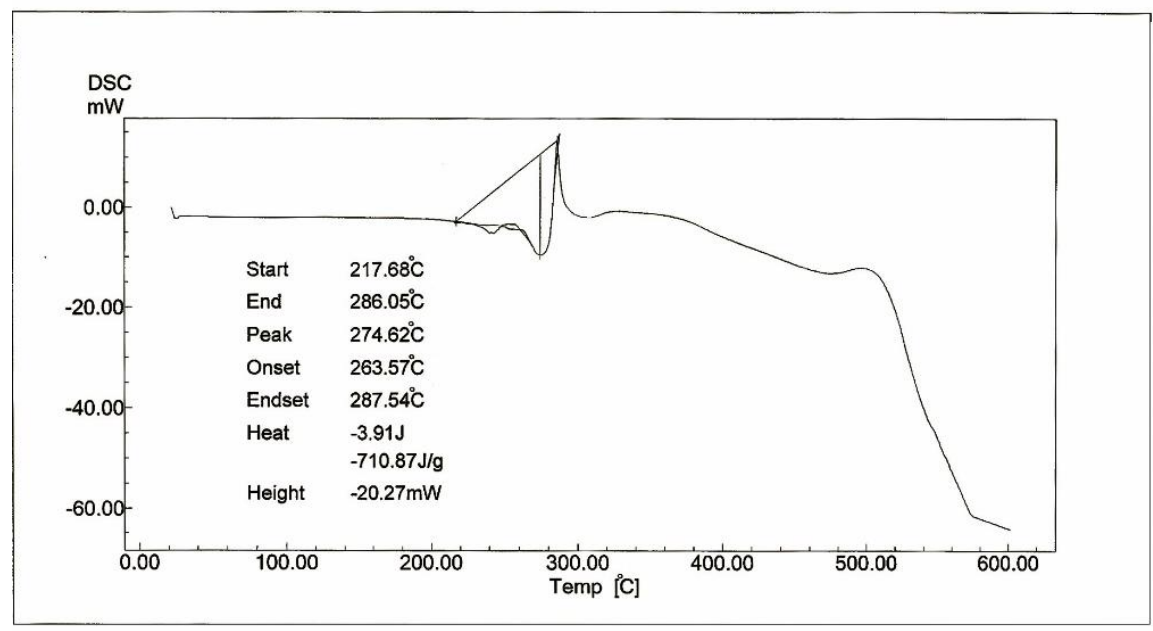

Figure $10 \mathrm{DSC}$ for $\mathrm{Hg}(\mathrm{TU})_{2} .4 \mathrm{H}_{2} \mathrm{O}$.

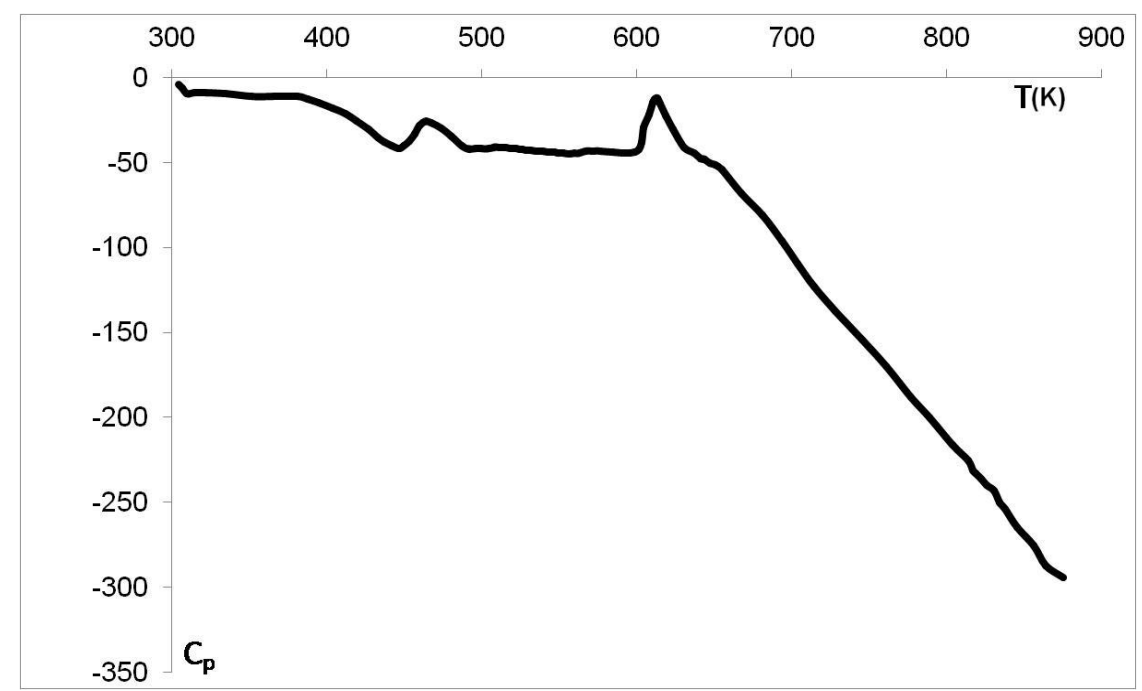


World Journal of Advanced Research and Reviews, 2021, 12(02), 078-108

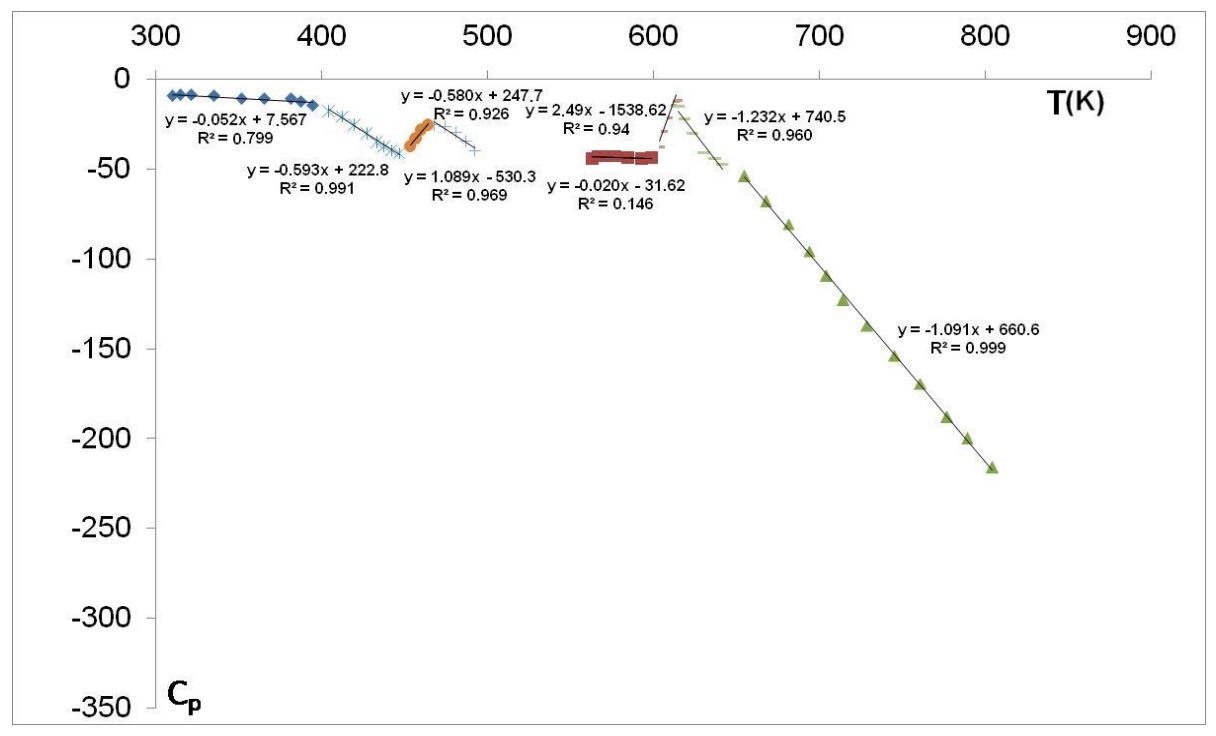

Figure 11a $\mathrm{Cp}$ - $\mathrm{T}$ relationship for $\mathrm{Fe}$ (adenine) 3.
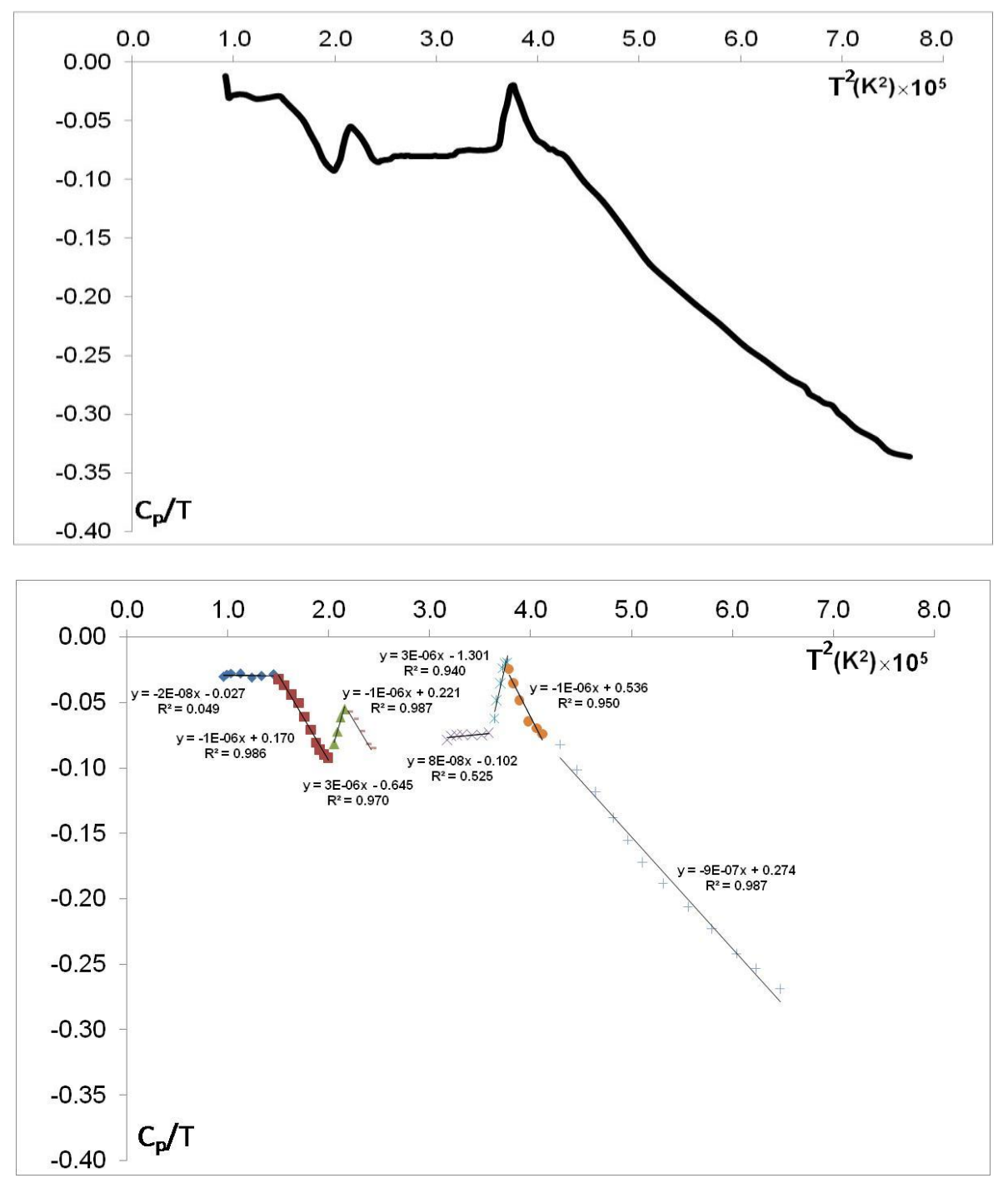

Figure 11b $\frac{c p}{T}-T^{2}$ relationship for Fe (adenine) . $_{3}$ 
World Journal of Advanced Research and Reviews, 2021, 12(02), 078-108

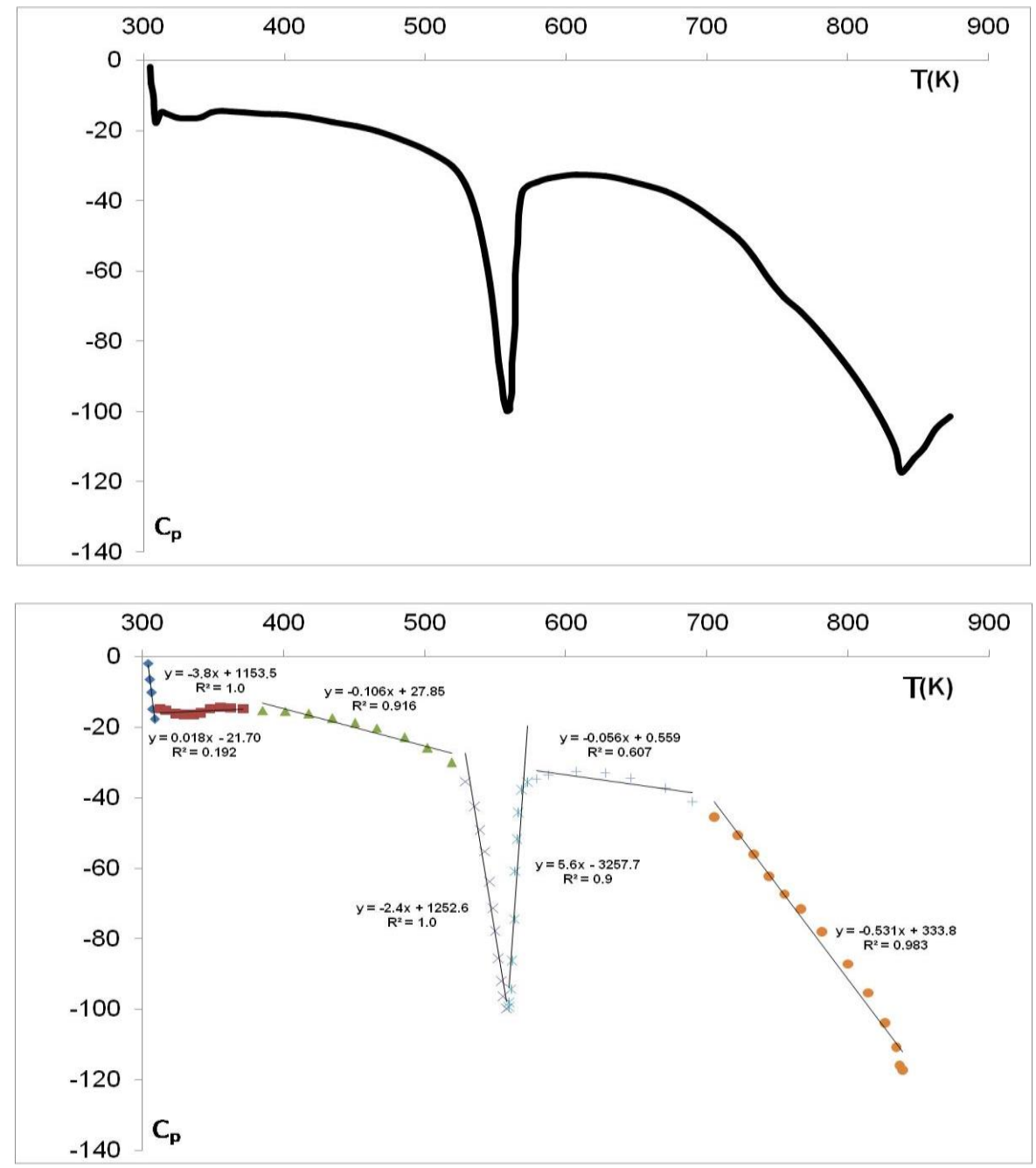

Figure 12a $\mathrm{Cp}$-T relationship for Co (acac) 2 (adenine).

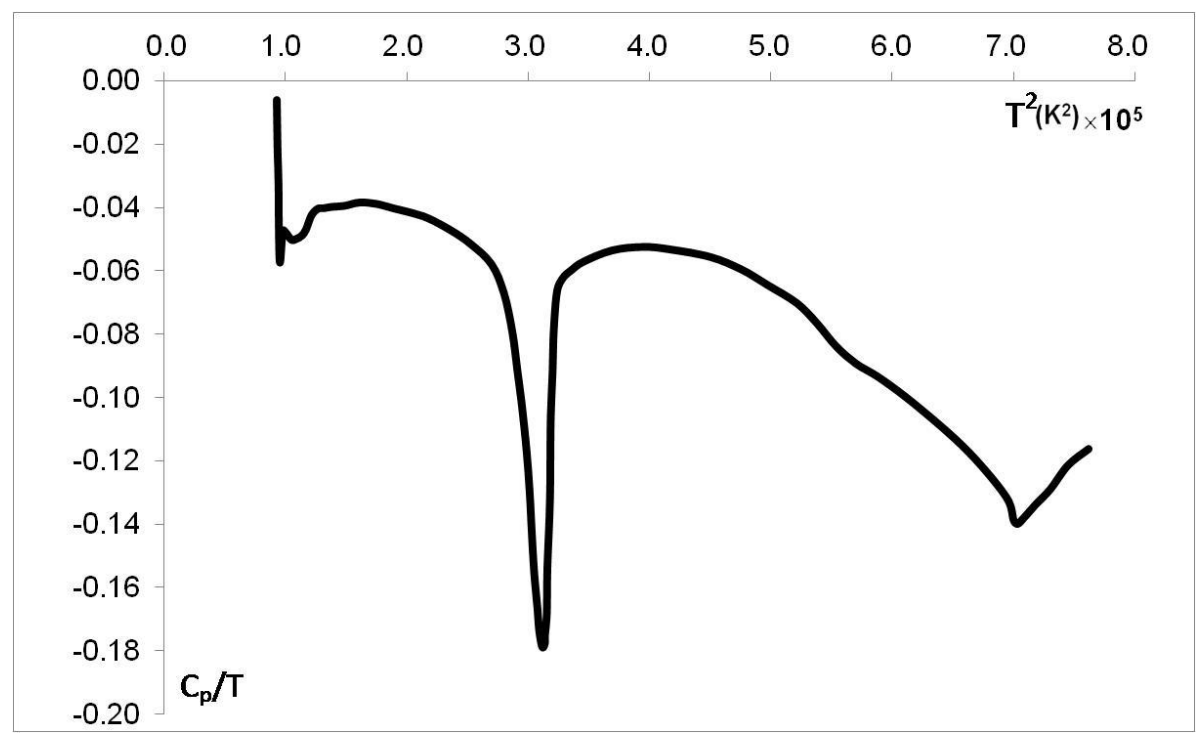


World Journal of Advanced Research and Reviews, 2021, 12(02), 078-108

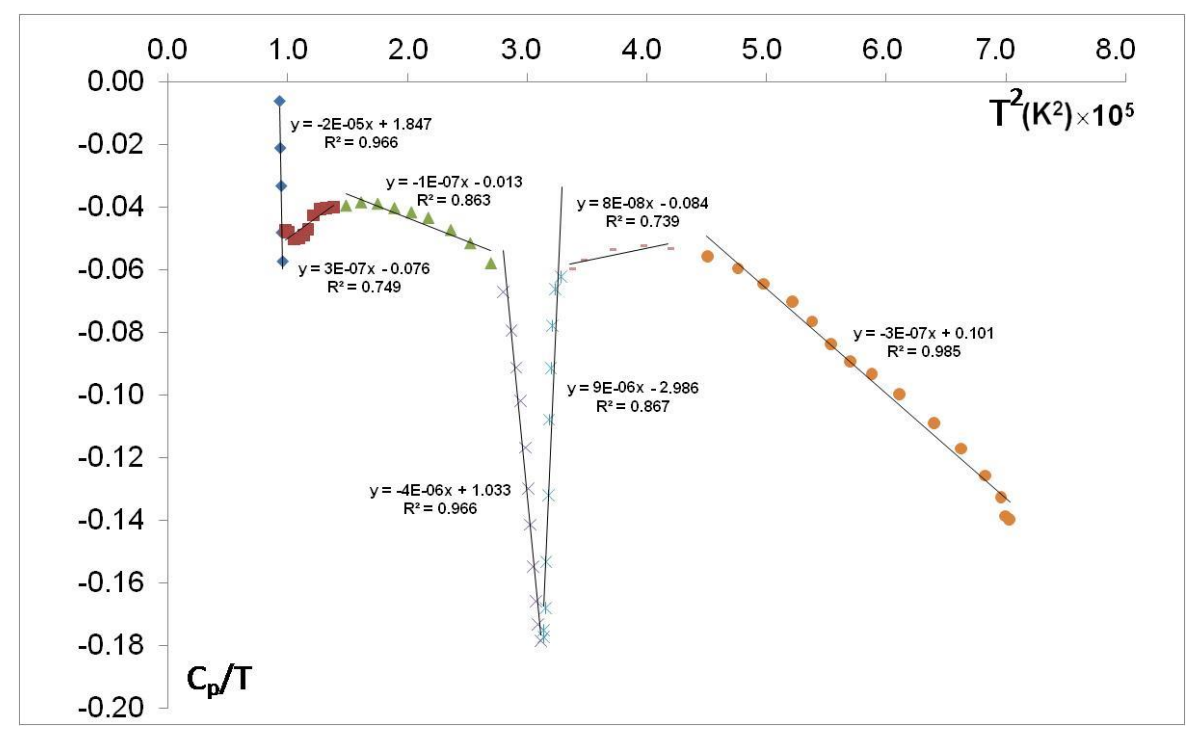

Figure $12 \mathbf{b} \frac{\boldsymbol{c} \boldsymbol{p}}{\boldsymbol{T}}-\mathrm{T}^{2}$ relationship for Co (acac)2 (adenine).

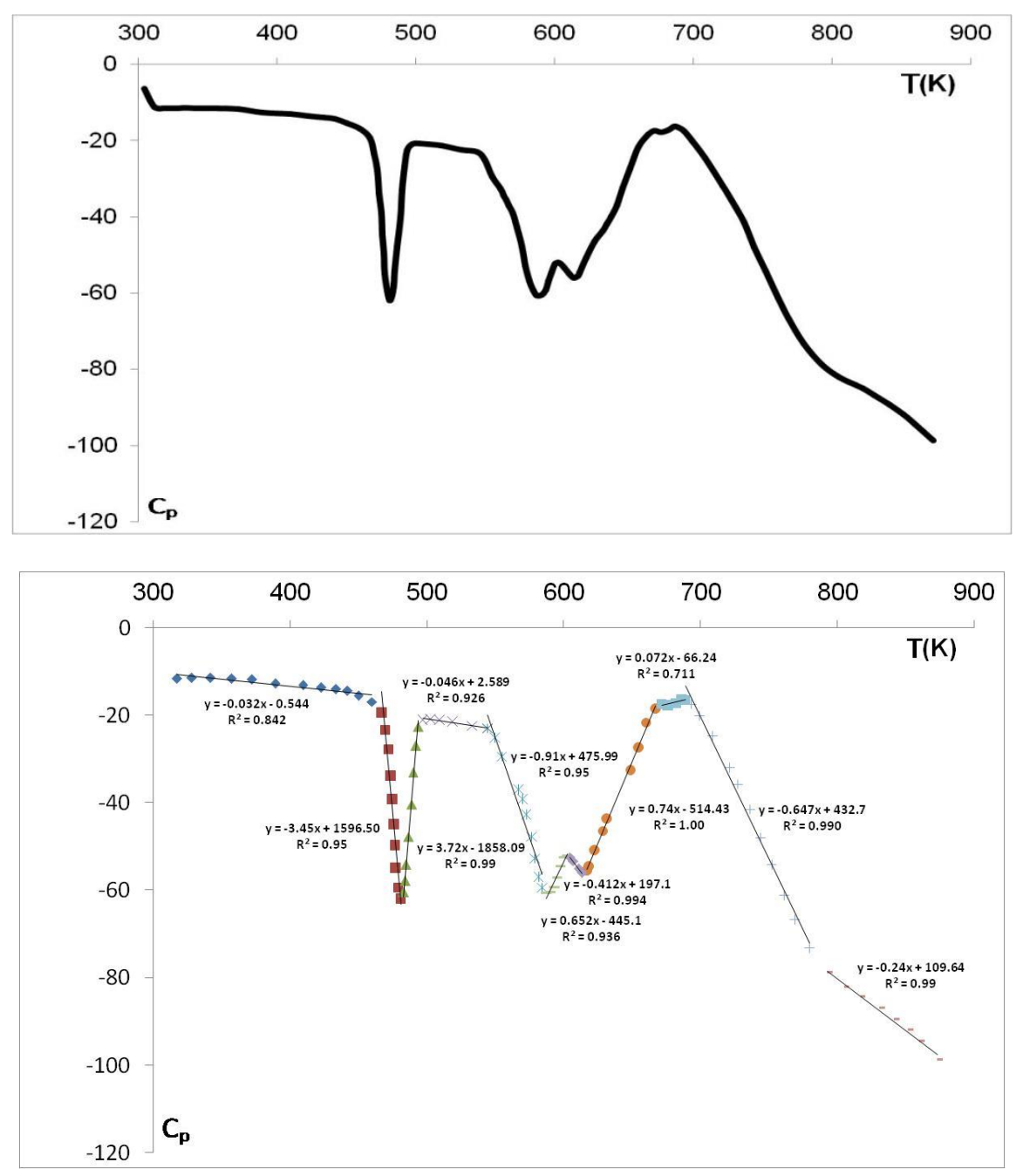

Figure 13a Cp - T relationship for $\mathrm{Zn}$ (hydroxyethyladenine) $)_{2}\left(\mathrm{OH}^{-}\right)_{2} \cdot 2 \mathrm{H}_{2} \mathrm{O}$. 
World Journal of Advanced Research and Reviews, 2021, 12(02), 078-108

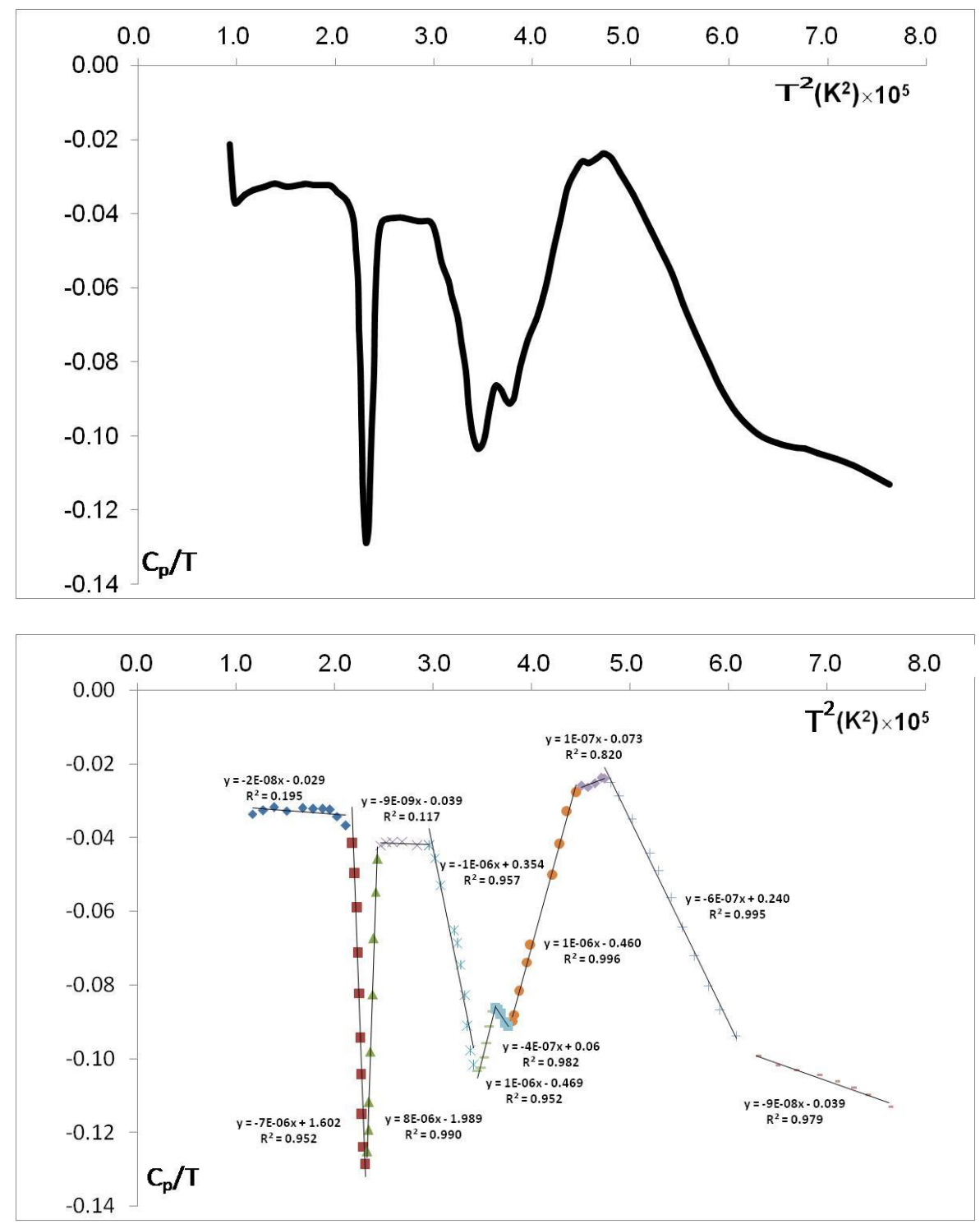

Figure 13b $\frac{\boldsymbol{c} \boldsymbol{p}}{\boldsymbol{T}}-\mathrm{T}^{2}$ relationship for $\mathrm{Zn}$ (hydroxyethyladenine) $)_{2}\left(\mathrm{OH}^{-}\right)_{2} \cdot 2 \mathrm{H}_{2} \mathrm{O}$.

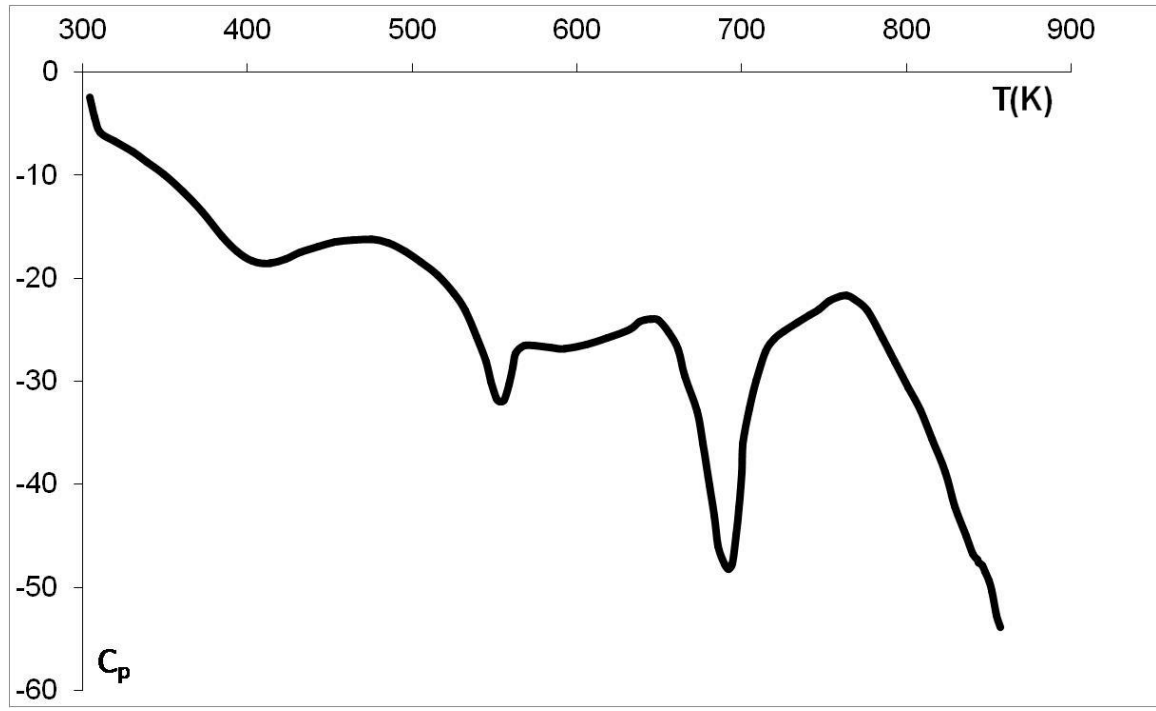


World Journal of Advanced Research and Reviews, 2021, 12(02), 078-108

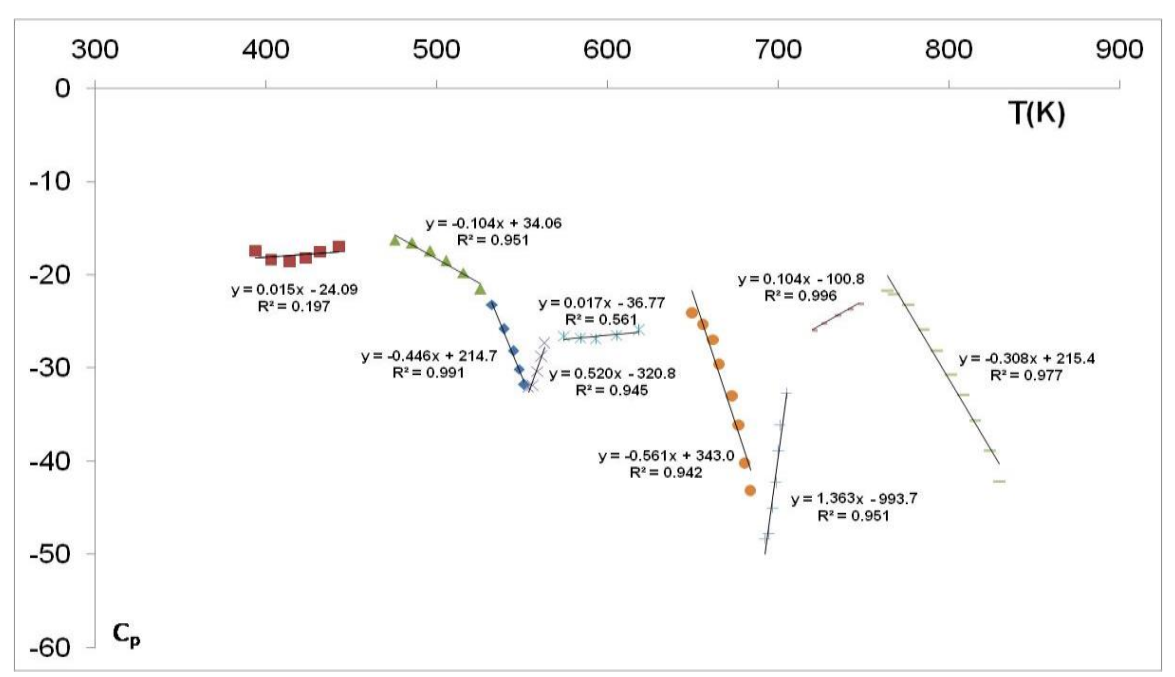

Figure 14a $\mathrm{Cp}-\mathrm{T}$ relationship for $\mathrm{Cr}(\mathrm{BA})\left(\mathrm{OH}^{-}\right) .4 \mathrm{H}_{2} \mathrm{O}$.
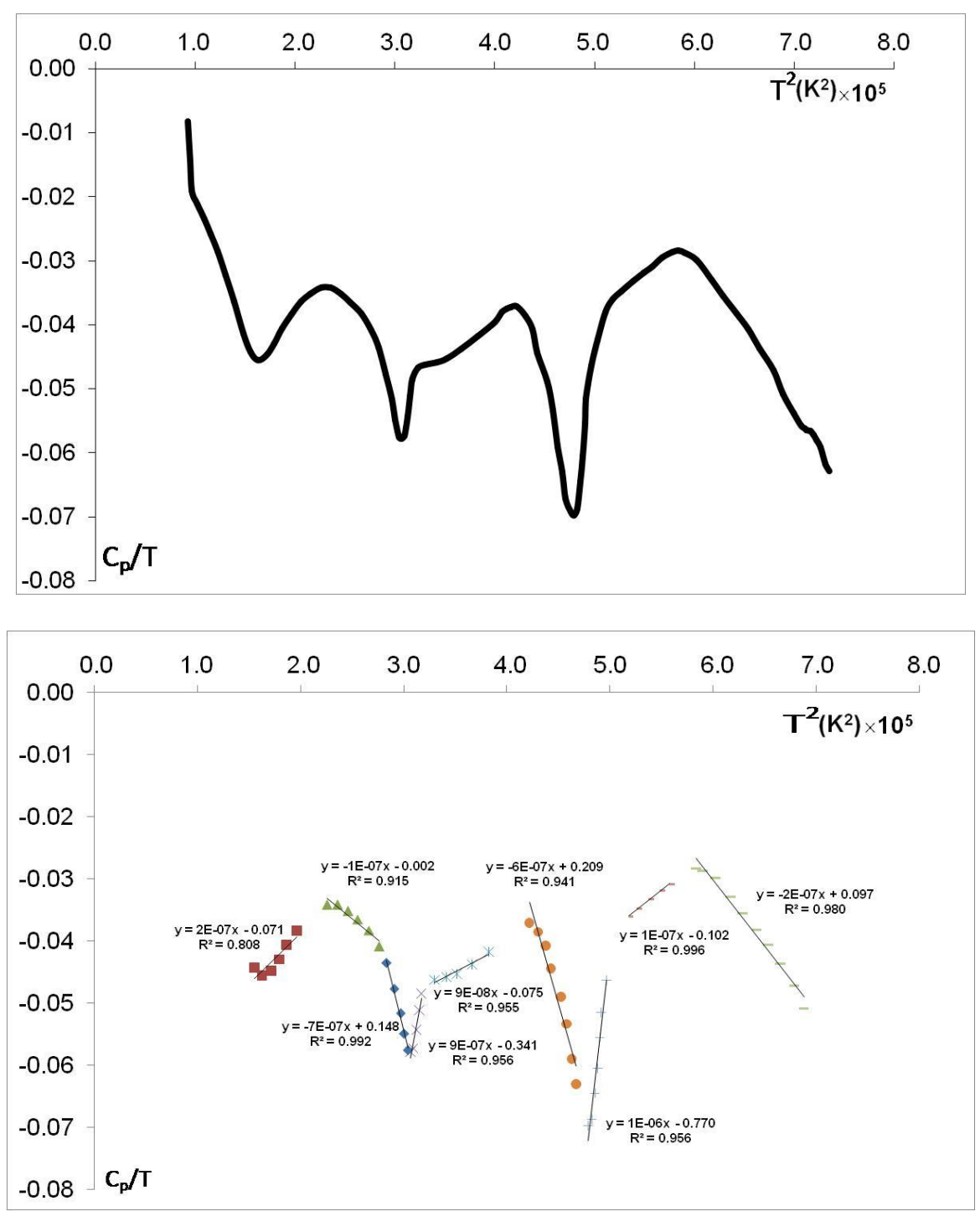

Figure 14b $\frac{c p}{T}-\mathrm{T}^{2}$ relationship for $\mathrm{Cr}(\mathrm{BA})\left(\mathrm{OH}^{-}\right) \cdot 4 \mathrm{H}_{2} \mathrm{O}$. 
World Journal of Advanced Research and Reviews, 2021, 12(02), 078-108
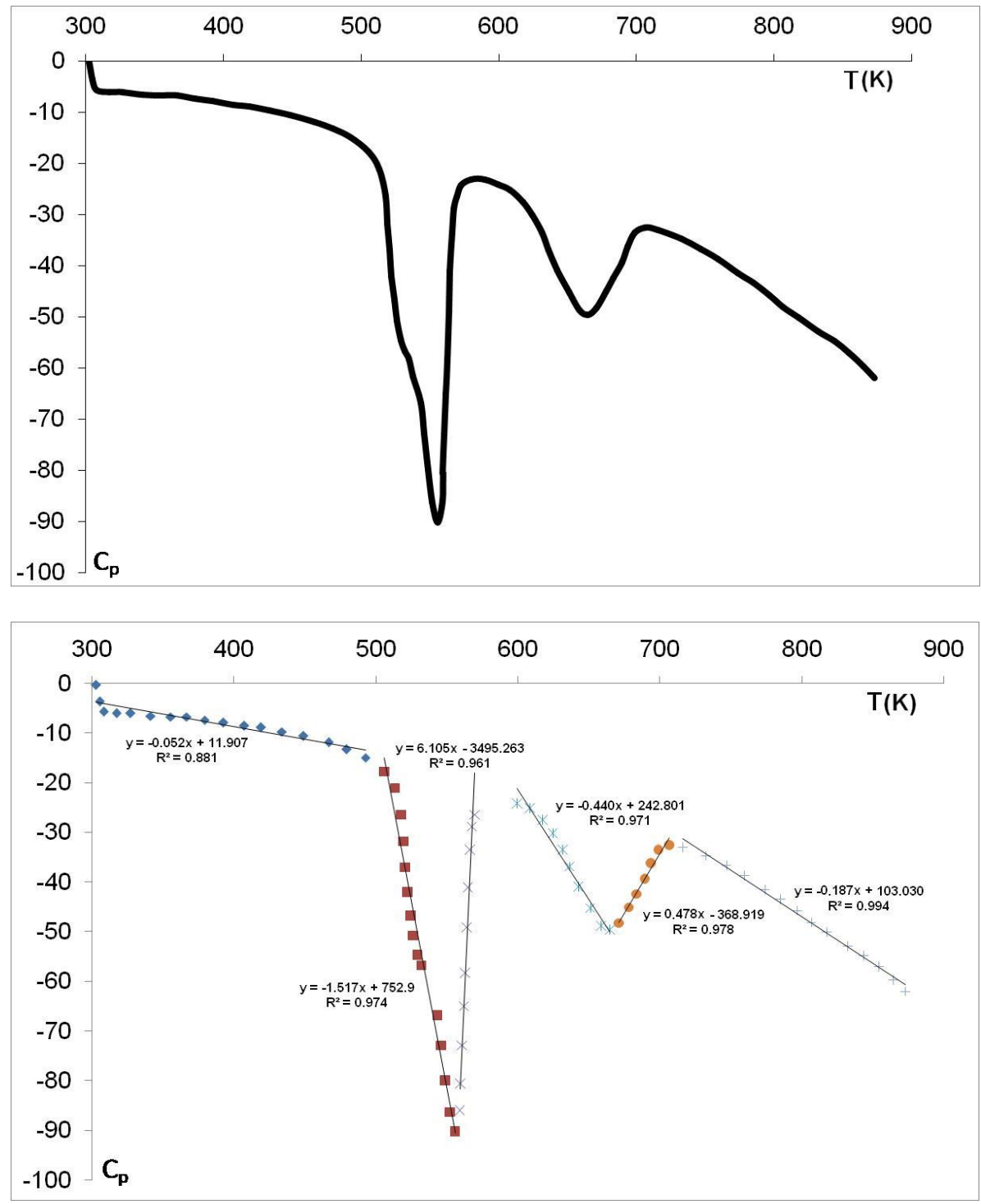

Figure 15a $\mathrm{Cp}$ - T relationship for $\mathrm{Zn}(\mathrm{BA})_{2} .3 \mathrm{H}_{2} \mathrm{O}$.

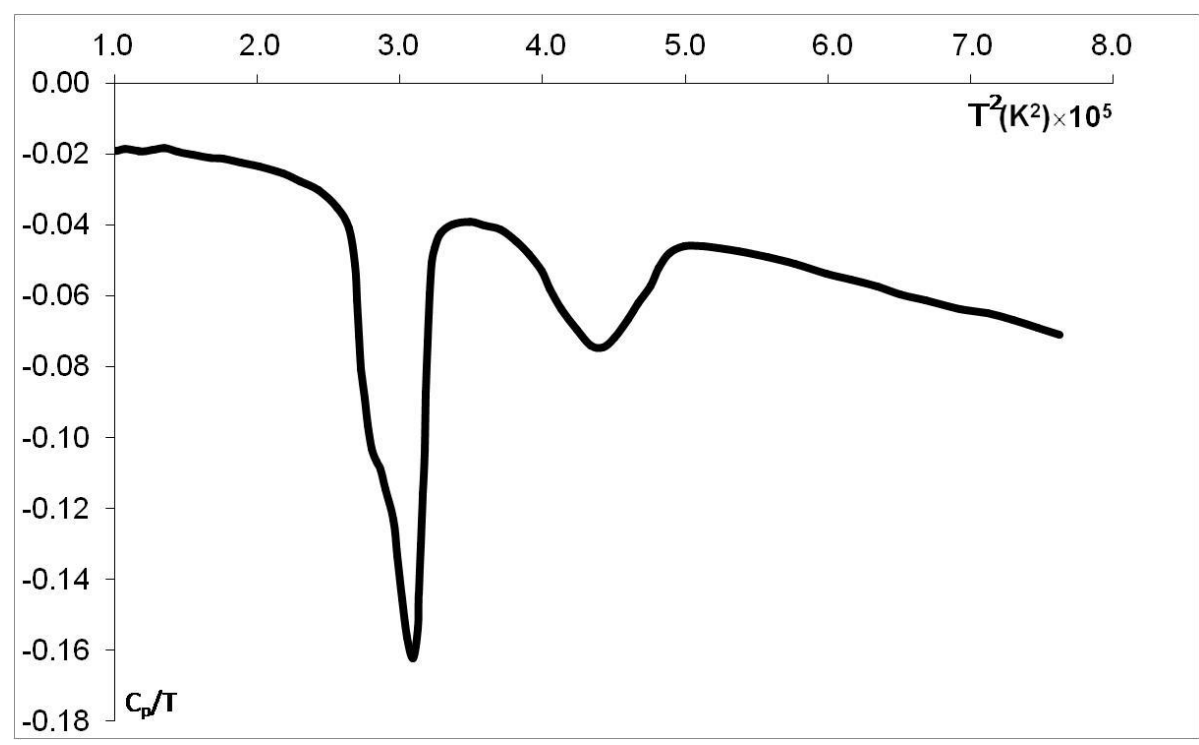


World Journal of Advanced Research and Reviews, 2021, 12(02), 078-108

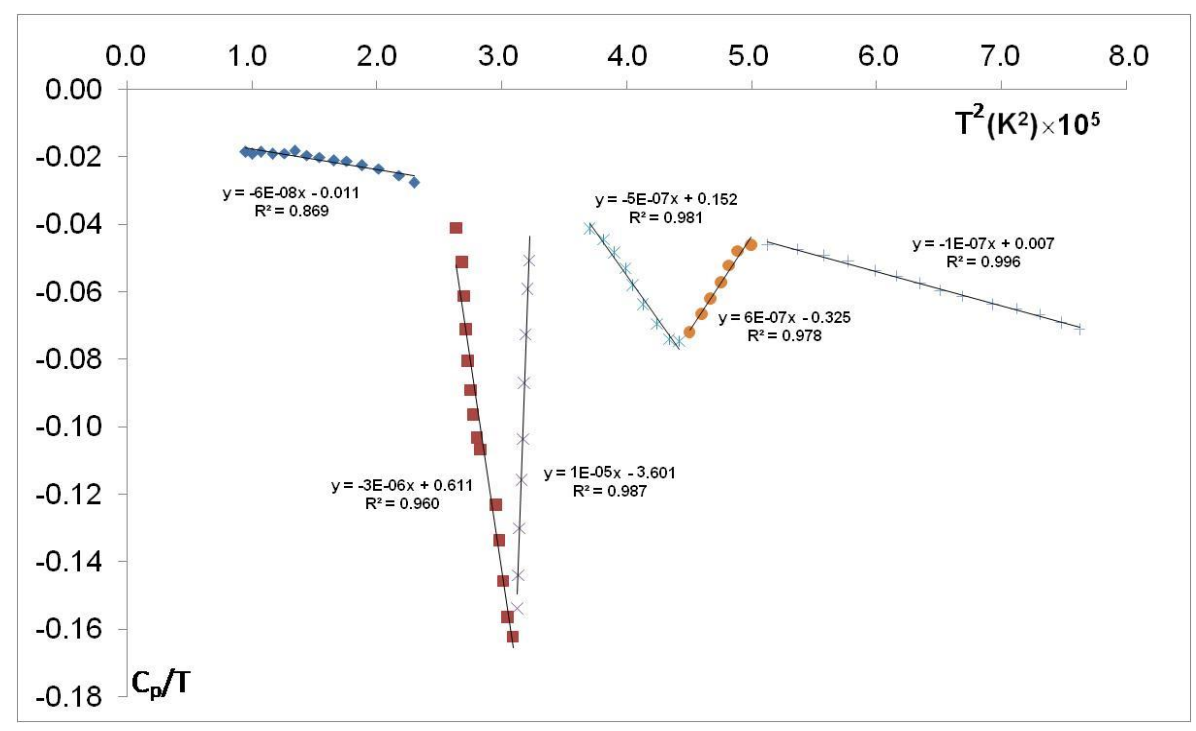

Figure 15b $\frac{c p}{T}-\mathrm{T}^{2}$ relationship for $\mathrm{Zn}(\mathrm{BA})_{2} .3 \mathrm{H}_{2} \mathrm{O}$.

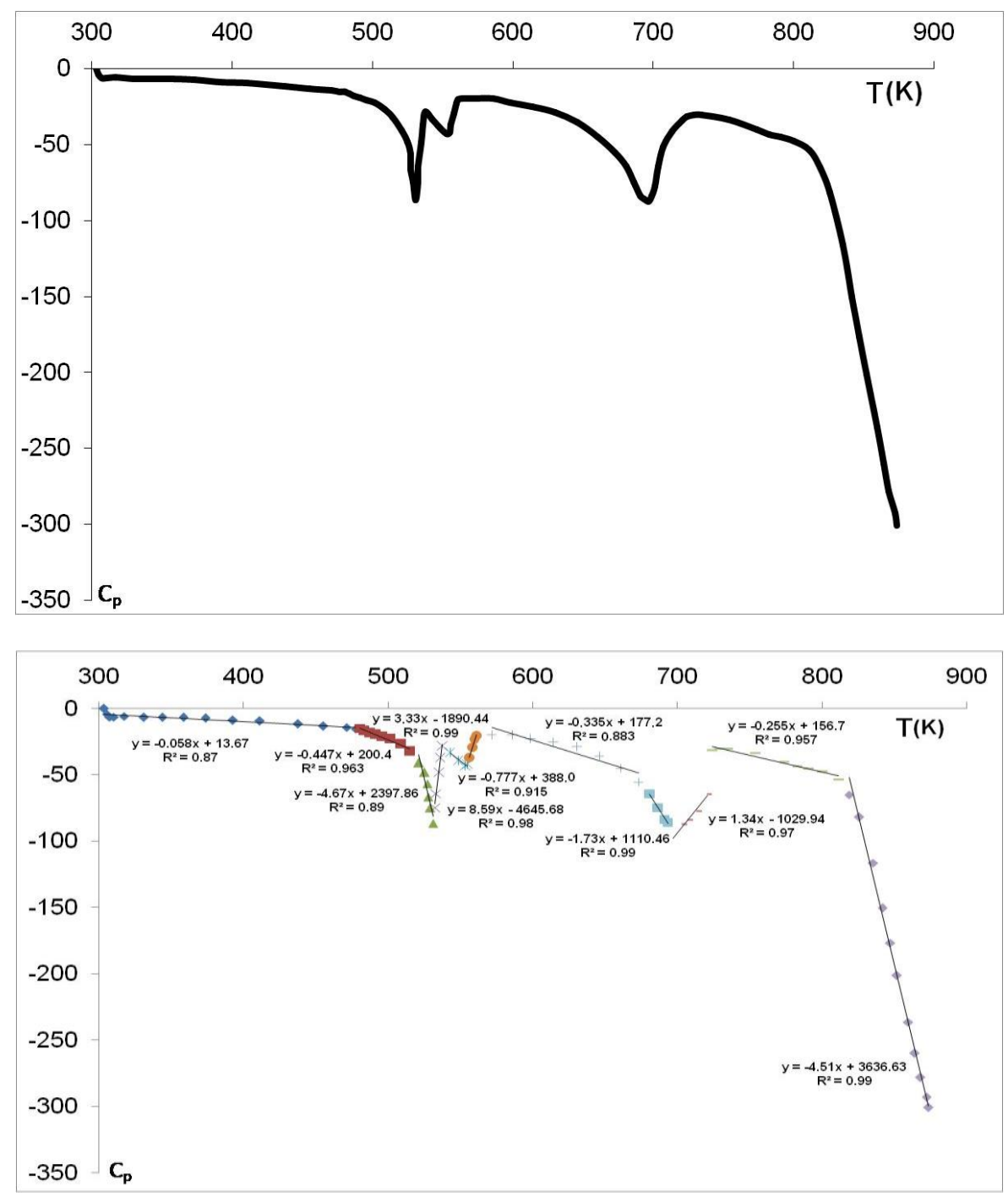

Figure 16a $\mathrm{Cp}$-T relationship for $\mathrm{Cd}(\mathrm{BA})_{2} \cdot 10 \mathrm{H}_{2} \mathrm{O}$. 
World Journal of Advanced Research and Reviews, 2021, 12(02), 078-108

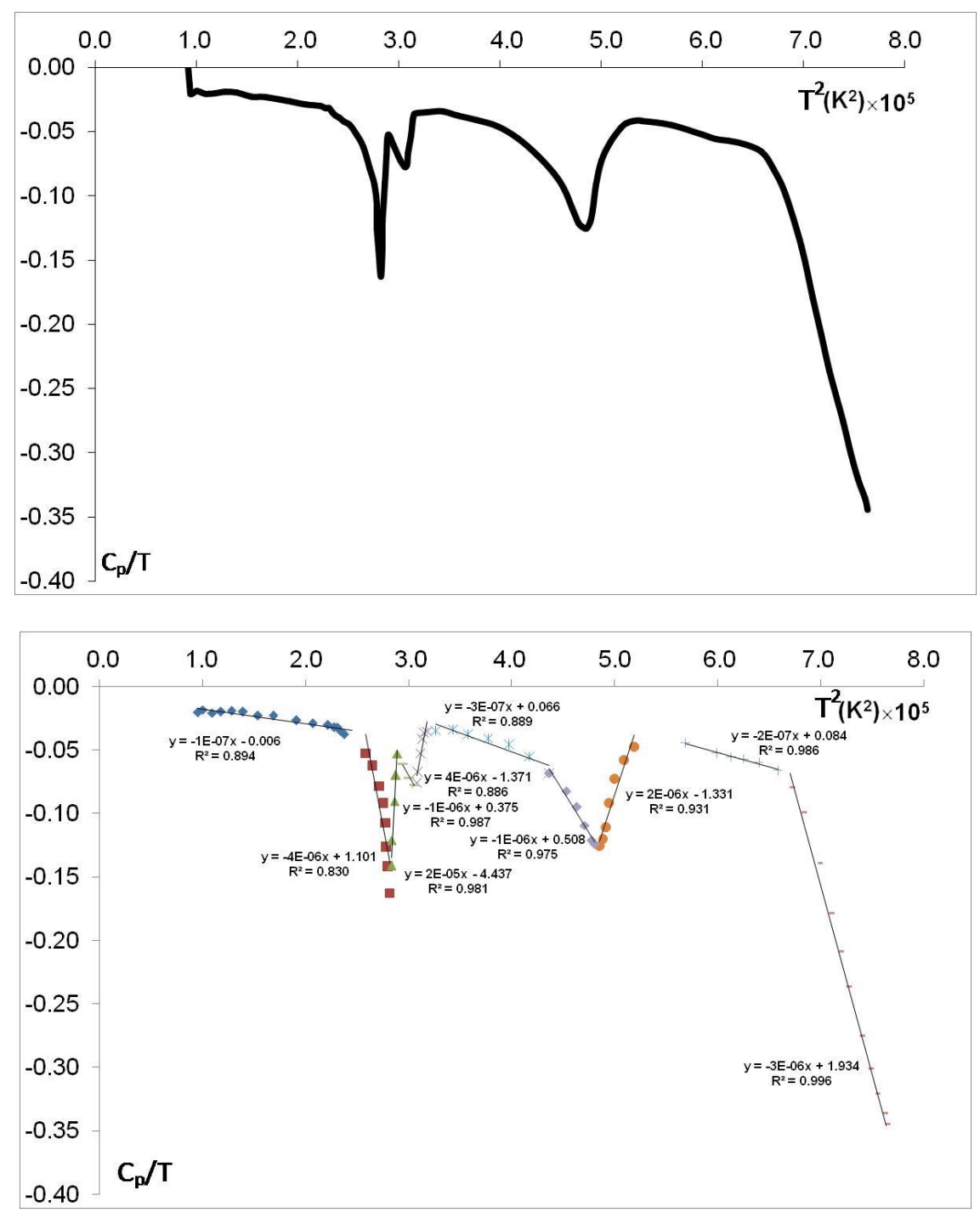

Figure 16b $\frac{C p}{T}-\mathrm{T}^{2}$ relationship for $\mathrm{Cd}(\mathrm{BA})_{2} \cdot 10 \mathrm{H}_{2} \mathrm{O}$.

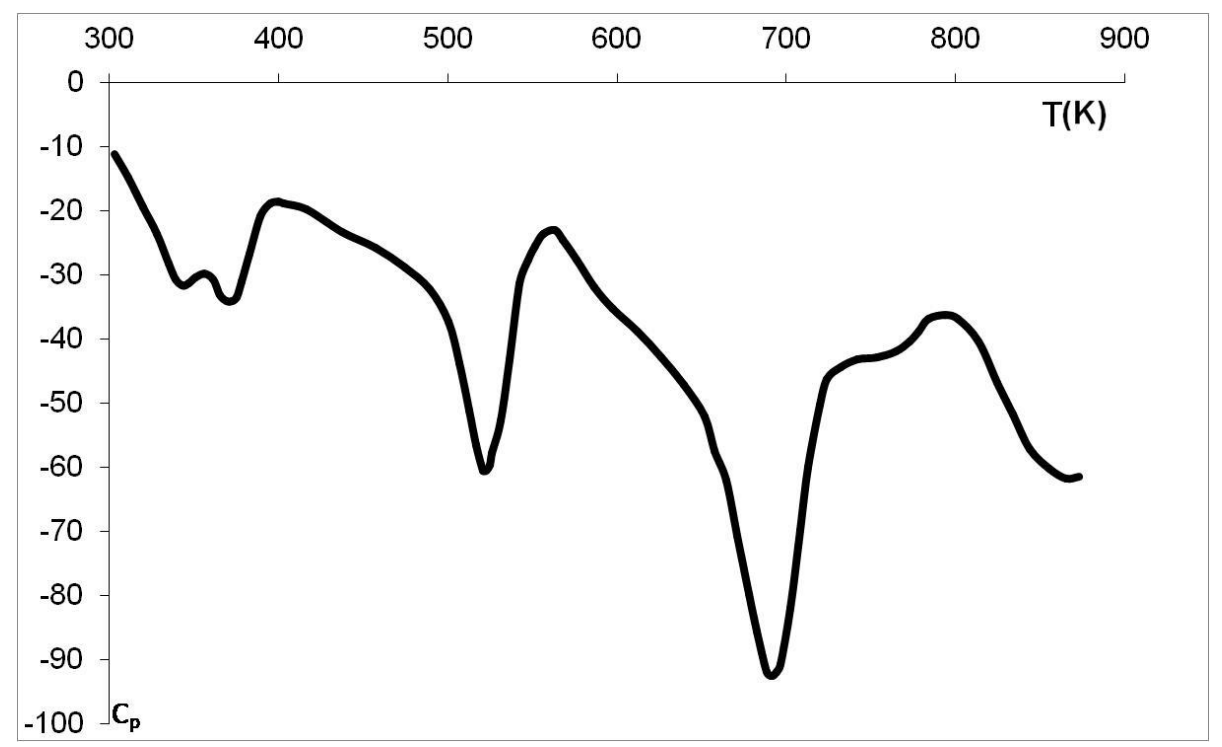


World Journal of Advanced Research and Reviews, 2021, 12(02), 078-108

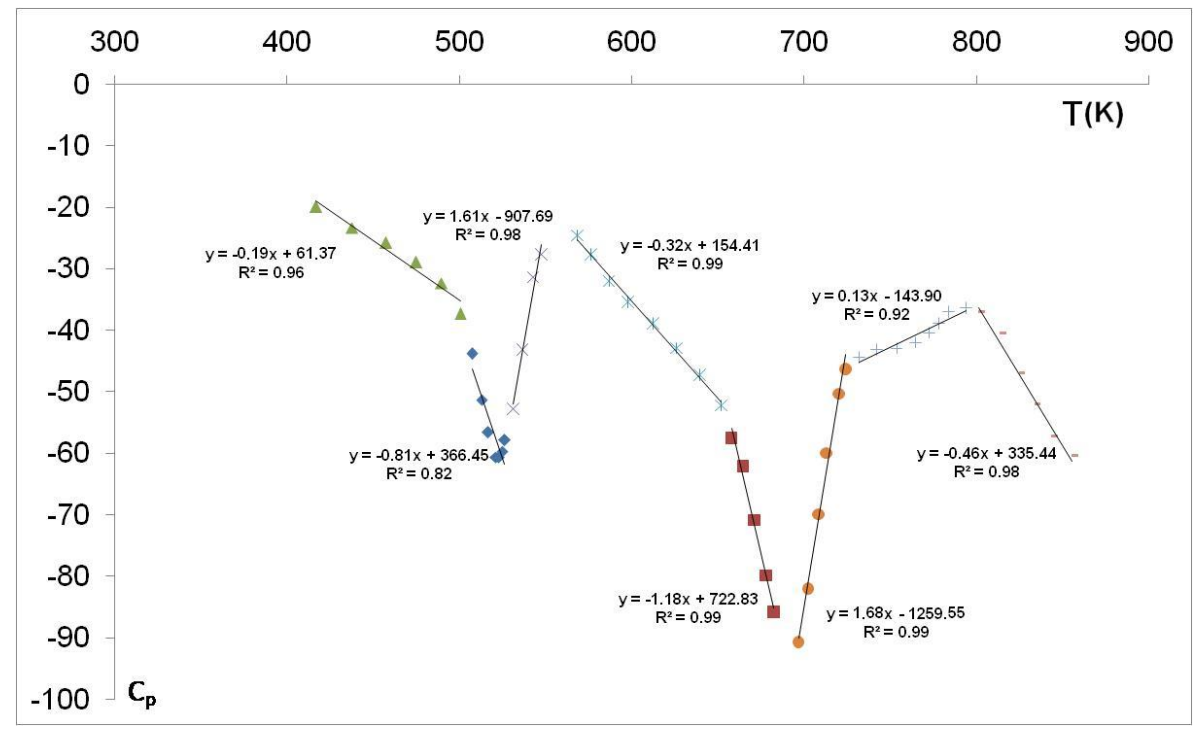

Figure 17a $\mathrm{Cp}$-T relationship for $\mathrm{Hg}(\mathrm{BA})_{2}$.
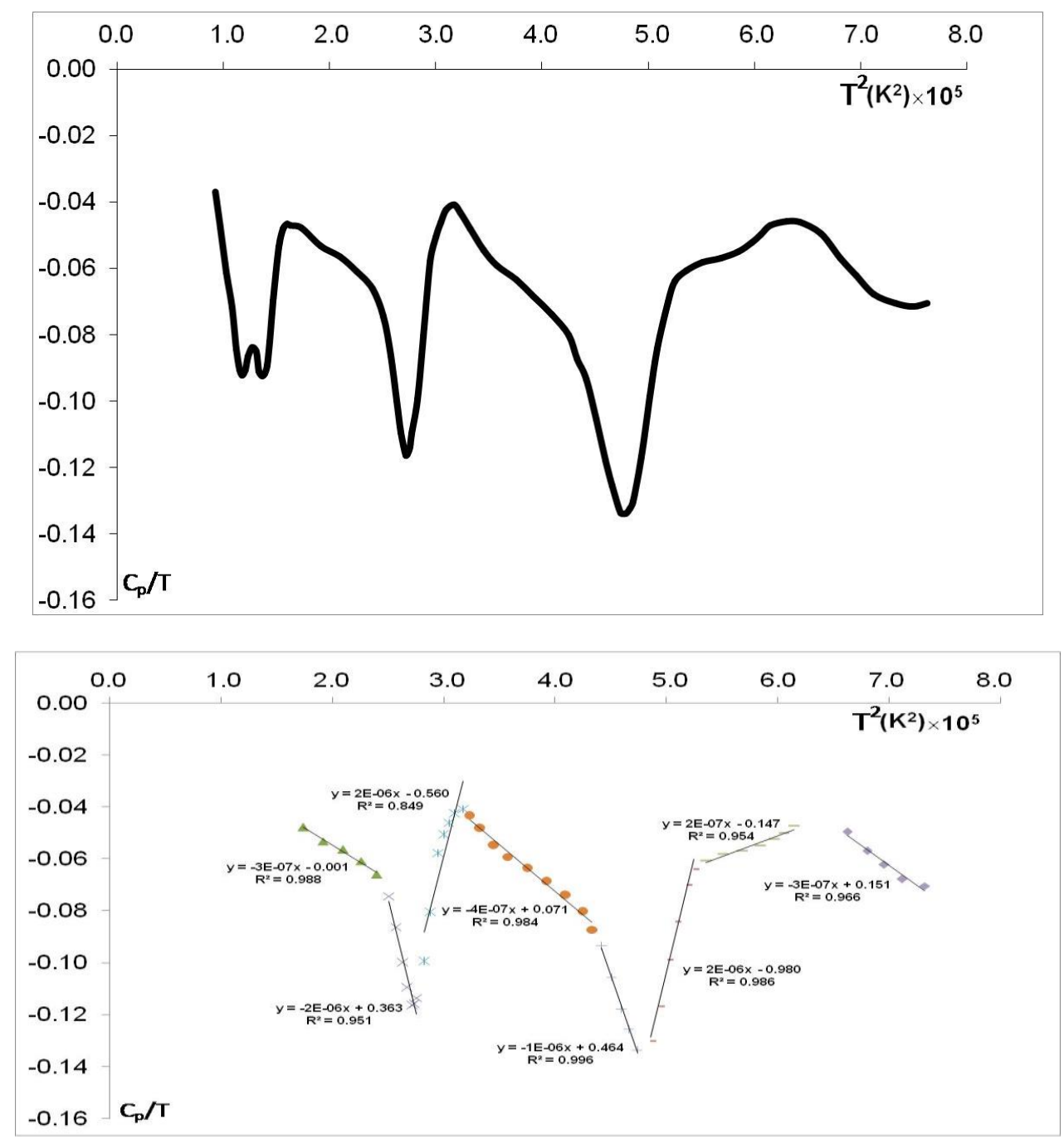

Figure $17 \mathbf{b} \frac{c p}{T}-\mathrm{T}^{2}$ relationship for $\mathrm{Hg}(\mathrm{BA})_{2}$. 
World Journal of Advanced Research and Reviews, 2021, 12(02), 078-108
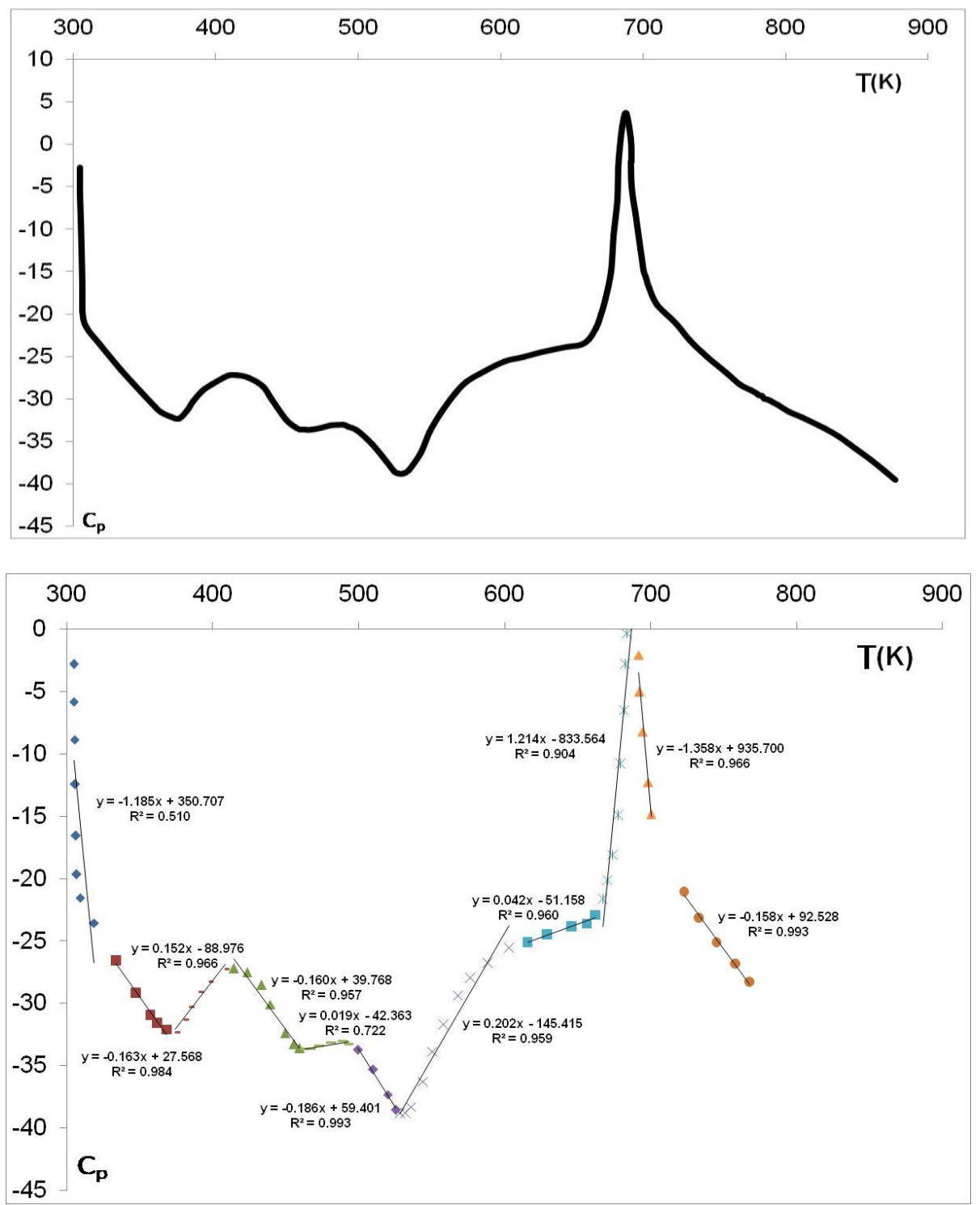

Figure 18a Cp -T relationship for Fe (TBA) $\left(\mathrm{OH}^{-}\right) \cdot 2 \mathrm{H}_{2} \mathrm{O}$.

\begin{tabular}{|c|c|c|c|c|c|c|c|c|c|}
\hline \multicolumn{2}{|c|}{0.0} & 1.0 & 2.0 & 3.0 & 4.0 & 5.0 & 6.0 & 7.0 & 8.0 \\
\hline 0.02 & & & & & & & & $\mathrm{~T}^{2}\left(\mathrm{~K}^{2}\right.$ & \\
\hline 0.00 & & & & & & & & & \\
\hline-0.02 & & & & & & & & & \\
\hline-0.04 & & & & & & & & & \\
\hline-0.06 & & & & & & & & & \\
\hline-0.08 & & & & & & & & & \\
\hline-0.10 & $C_{p} / T$ & & & & & & & & \\
\hline
\end{tabular}


World Journal of Advanced Research and Reviews, 2021, 12(02), 078-108

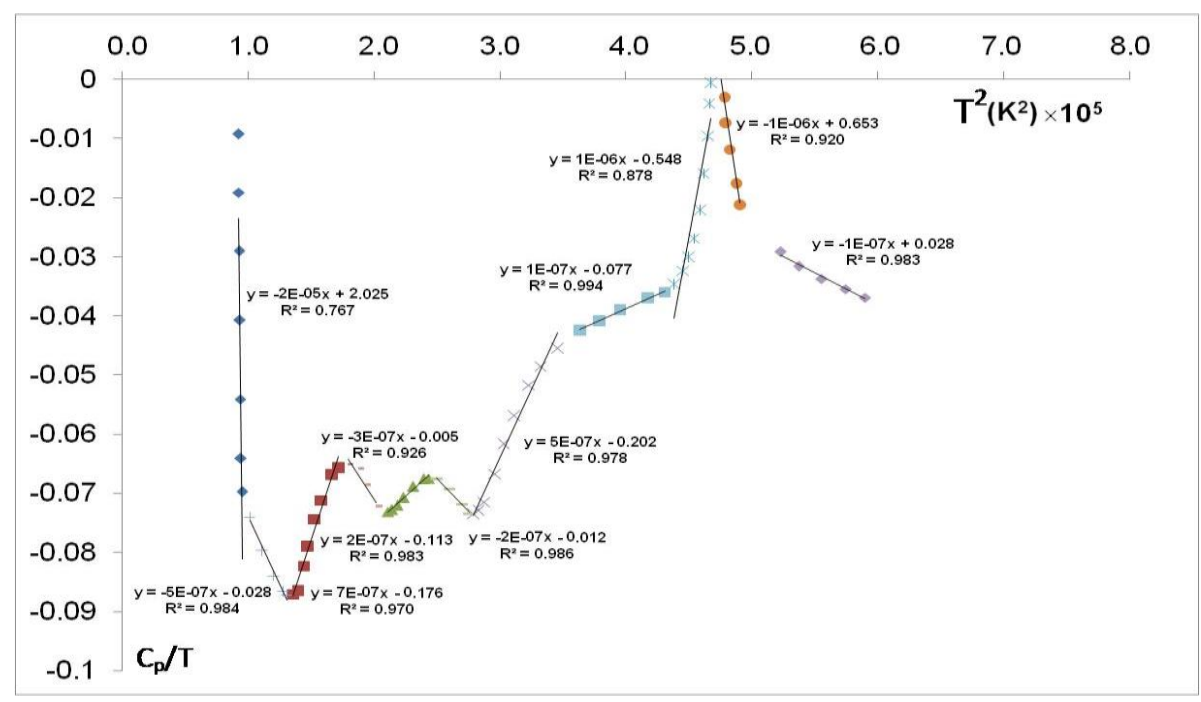

Figure 18b $\frac{c p}{T}-\mathrm{T}^{2}$ relationship for Fe (TBA) $\left(\mathrm{OH}^{-}\right) .2 \mathrm{H}_{2} \mathrm{O}$.

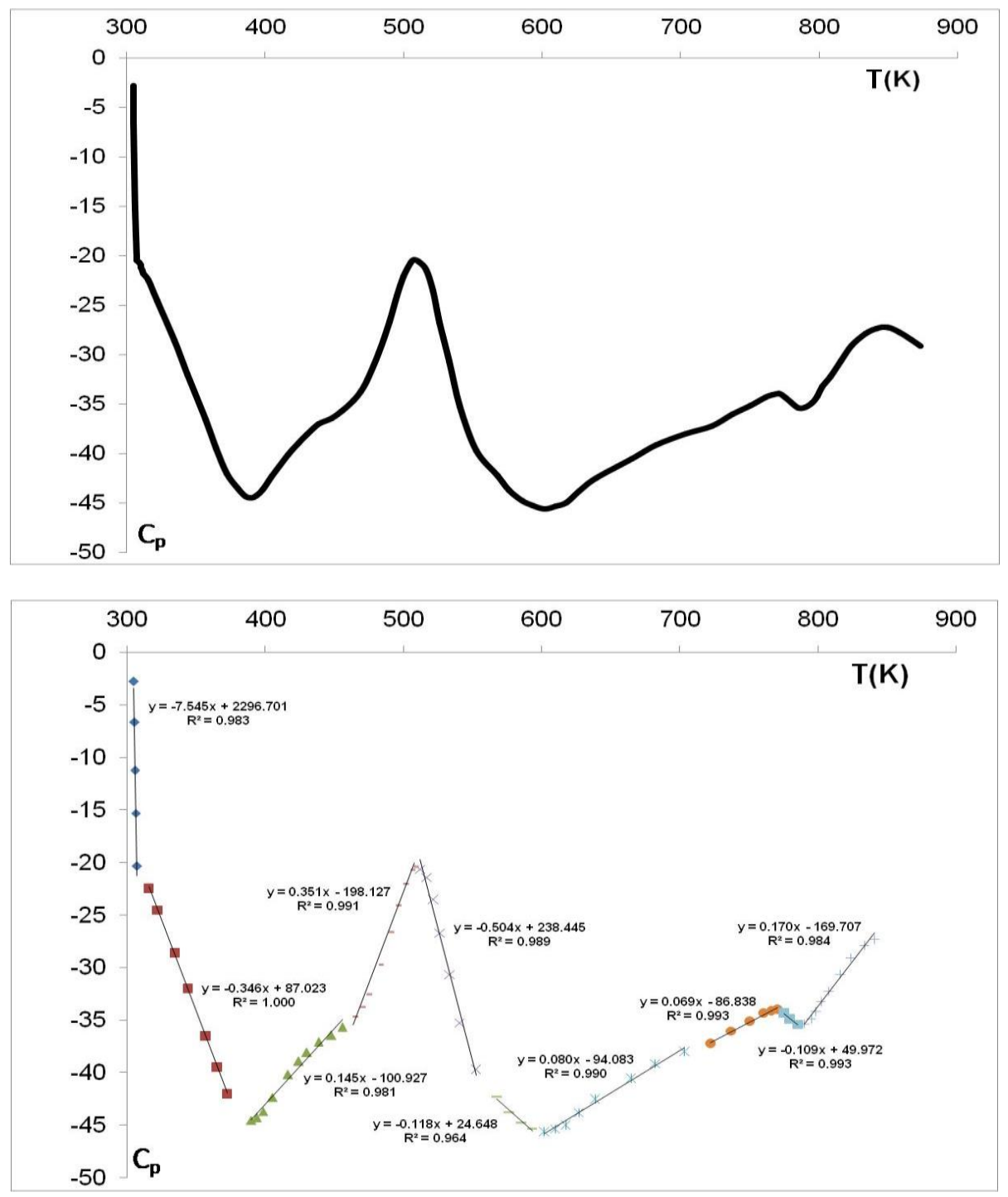

Figure 19a $\mathrm{Cp}$ - $\mathrm{T}$ relationship for $\mathrm{Cr}(\mathrm{TU})\left(\mathrm{OH}^{-}\right)_{2} \cdot \mathrm{H}_{2} \mathrm{O}$. 
World Journal of Advanced Research and Reviews, 2021, 12(02), 078-108

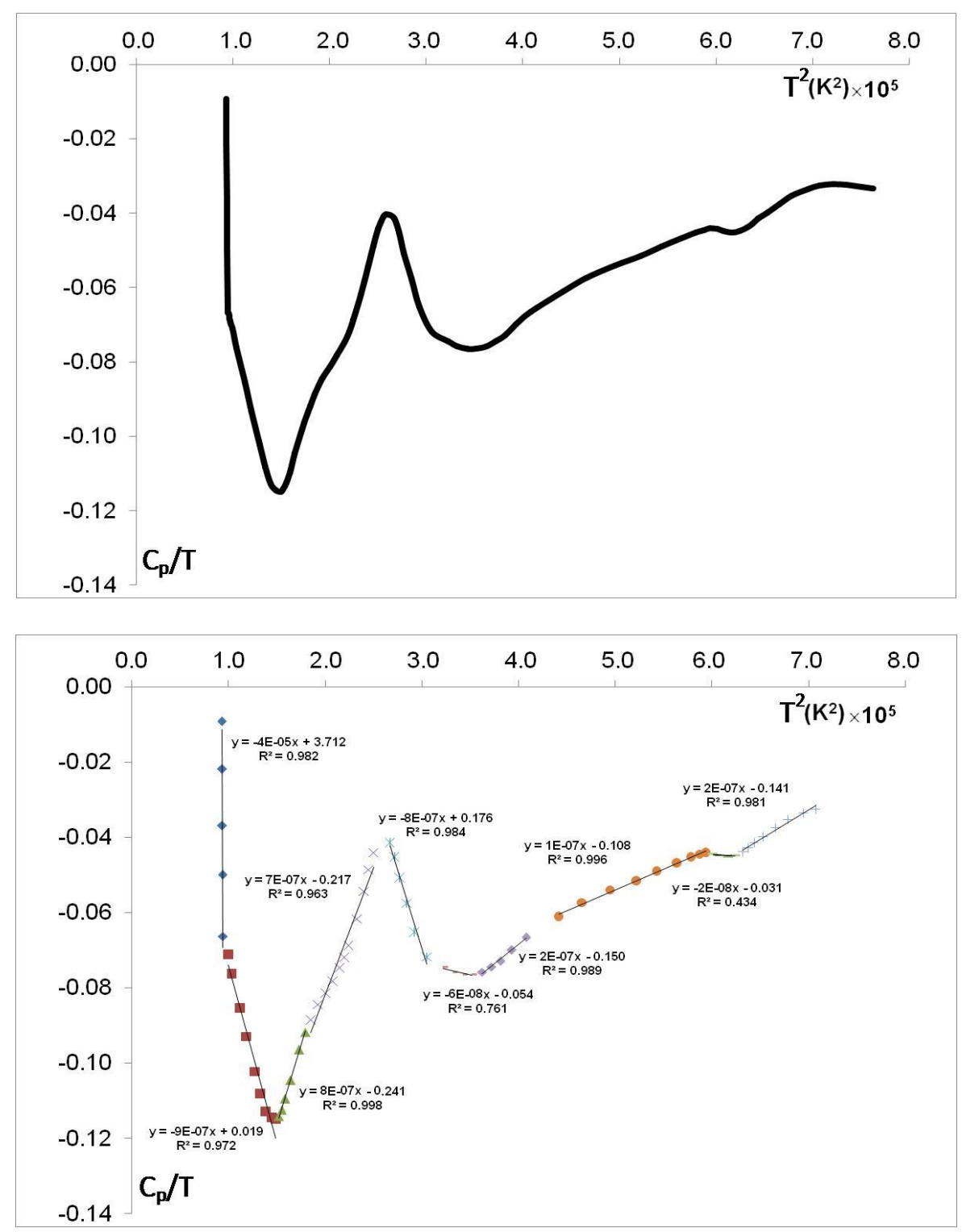

Figure 19b $\frac{c p}{\boldsymbol{T}}-\mathrm{T}^{2}$ relationship for $\mathrm{Cr}(\mathrm{TU})\left(\mathrm{OH}^{-}\right)_{2} \cdot \mathrm{H}_{2} \mathrm{O}$.

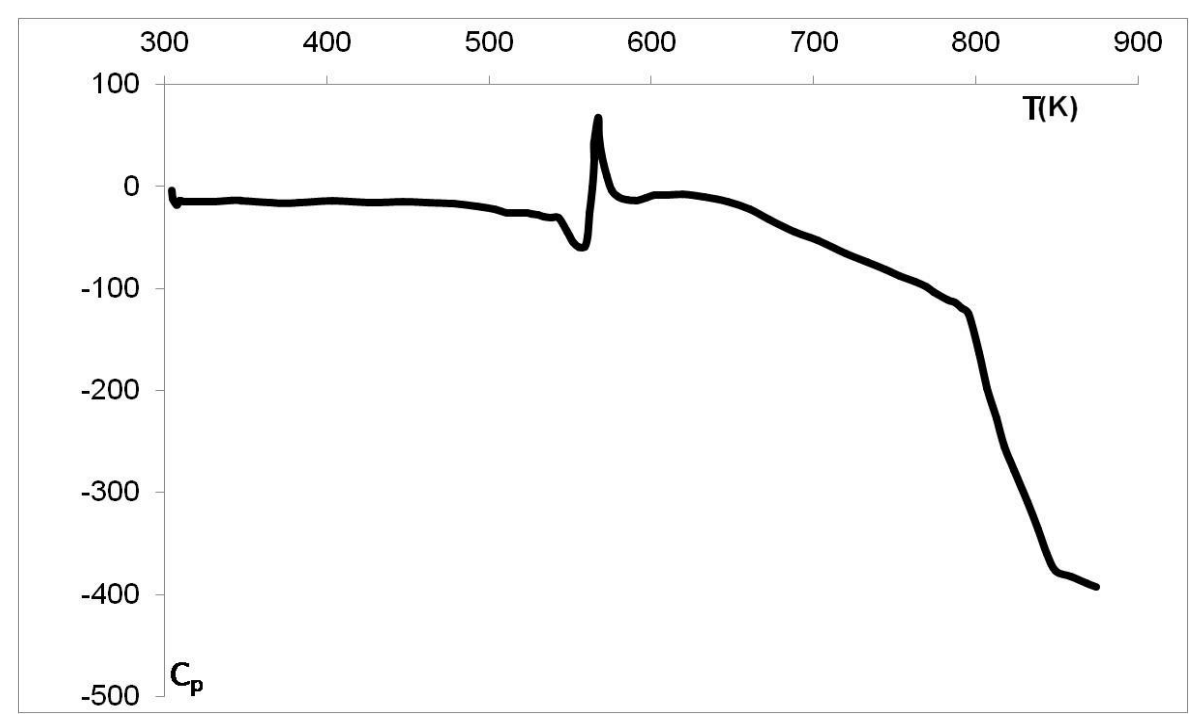


World Journal of Advanced Research and Reviews, 2021, 12(02), 078-108

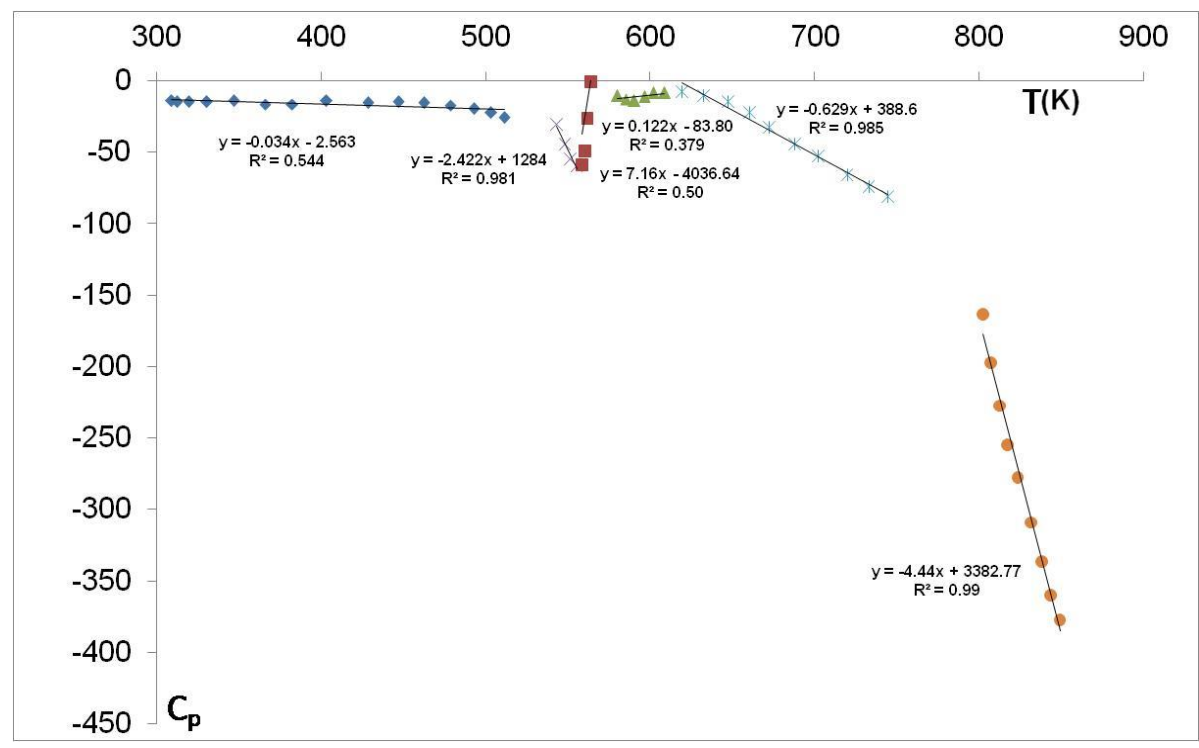

Figure 20a $\mathrm{Cp}-\mathrm{T}$ relationship for $\mathrm{Hg}(\mathrm{TU})_{2} .4 \mathrm{H}_{2} \mathrm{O}$.
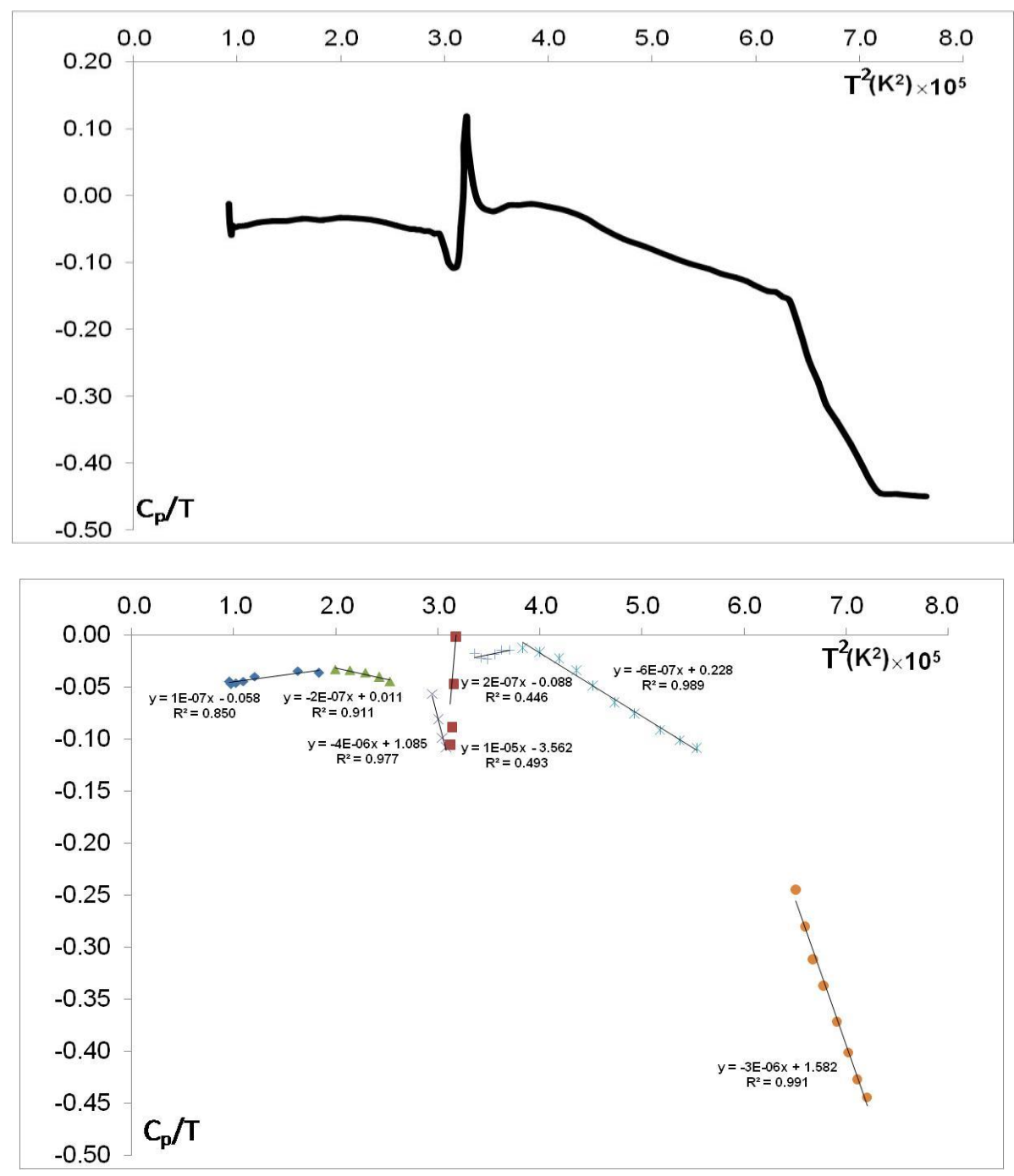

Figure 20b $\frac{c p}{T}-\mathrm{T}^{2}$ relationship for $\mathrm{Hg}(\mathrm{TU})_{2} .4 \mathrm{H}_{2} \mathrm{O}$. 
The change in enthalpy $(\Delta \mathrm{H})$ for any phase transformation [24]taking place at any peak temperature, $\mathrm{T}_{\mathrm{m}}$, can be given by the following equation:

$$
\Delta S=\frac{\Delta H}{\mathrm{~T}_{\mathrm{m}}} \quad \text { (at equilibrium, } \Delta \mathrm{G}=0 \text { ) }
$$

The values of $T_{m}$ (the peak temperature at which the peak is maximum or minimum), $\Delta H, \Delta S,(a, b)$ parameters of Debye model, $\alpha$ and $\gamma$ are given in Table (2).

Table 2 DSC data and thermodynamic paramerters of the complexes*.

\begin{tabular}{|c|c|c|c|c|c|c|c|c|}
\hline Compound & $\begin{array}{l}\text { Heat range } \\
{ }^{\circ} \mathrm{C}\end{array}$ & $\begin{array}{l}\mathrm{T}_{\mathbf{m}} \\
{ }^{\circ} \mathrm{C}\end{array}$ & $\begin{array}{l}\Delta \mathbf{H} \\
\mathrm{J} / \mathrm{g}\end{array}$ & $\begin{array}{l}\Delta S \\
\mathrm{~J} / \mathrm{g} .{ }^{\circ} \mathrm{C}\end{array}$ & $\mathbf{a}$ & $\mathbf{b}$ & $\alpha$ & $\gamma$ \\
\hline $\mathrm{Fe}$ (adenine) 3 & $109.92-183.78$ & 163.54 & -128.22 & -0.784 & $\begin{array}{l}-0.052 \\
-0.593 \\
1.089 \\
-0.580 \\
0.020 \\
2.490 \\
-1.232 \\
-1.091\end{array}$ & $\begin{array}{l}7.567 \\
222.842 \\
-530.338 \\
247.741 \\
-31.629 \\
-1538.618 \\
740.526 \\
660.690\end{array}$ & $\begin{array}{l}-2 \times 10^{-8} \\
-1 \times 10^{-6} \\
3 \times 10^{-6} \\
-1 \times 10^{-6} \\
8 \times 10^{-8} \\
3 \times 10^{-6} \\
-1 \times 10^{-6} \\
-9 \times 10^{-7}\end{array}$ & $\begin{array}{l}-0.027 \\
0.170 \\
-0.645 \\
0.221 \\
-0.102 \\
-1.301 \\
0.536 \\
0.274\end{array}$ \\
\hline Co (acac) 2 (adenine) & $223.55-297.22$ & 278.19 & -278.42 & -1.001 & $\begin{array}{l}-3.795 \\
0.018 \\
-0.106 \\
-2.420 \\
5.649 \\
-0.056 \\
0.531\end{array}$ & $\begin{array}{l}1153.536 \\
-21.704 \\
27.857 \\
1252.625 \\
-3257.739 \\
0.559 \\
333.876\end{array}$ & $\begin{array}{l}-2 \times 10^{-5} \\
3 \times 10^{-7} \\
-1 \times 10^{-7} \\
-4 \times 10^{-6} \\
9 \times 10^{-6} \\
8 \times 10^{-8} \\
-3 \times 10^{-7}\end{array}$ & $\begin{array}{l}1.847 \\
-0.076 \\
-0.013 \\
1.033 \\
-2.986 \\
-0.084 \\
0.101\end{array}$ \\
\hline $\begin{array}{l}\mathrm{Zn} \\
\text { (hydroxyethyladen } \\
\text { ine })_{2}\left(\mathrm{OH}^{-}\right)_{2} \cdot 2 \mathrm{H}_{2} \mathrm{O}\end{array}$ & $\begin{array}{l}175.77-216.76 \\
263.45-391.26\end{array}$ & $\begin{array}{l}199.56 \\
309.58\end{array}$ & $\begin{array}{l}-121.39 \\
-539.20\end{array}$ & $\begin{array}{l}-0.608 \\
-1.742\end{array}$ & $\begin{array}{l}-0.032 \\
-3.450 \\
3.721 \\
-0.046 \\
-0.911 \\
0.653 \\
-0.413 \\
0.744 \\
0.072 \\
-0.647 \\
-0.237\end{array}$ & $\begin{array}{l}-0.544 \\
1596.504 \\
-1858.094 \\
2.589 \\
475.988 \\
-445.182 \\
197.110 \\
-514.426 \\
-66.241 \\
432.769 \\
109.642\end{array}$ & $\begin{array}{l}-2 \times 10^{-8} \\
-7 \times 10^{-6} \\
8 \times 10^{-6} \\
-9 \times 10^{-9} \\
-1 \times 10^{-6} \\
1 \times 10^{-6} \\
-4 \times 10^{-7} \\
1 \times 10^{-6} \\
1 \times 10^{-7} \\
-6 \times 10^{-7} \\
-9 \times 10^{-8}\end{array}$ & $\begin{array}{l}-0.029 \\
1.602 \\
-1.989 \\
-0.039 \\
0.354 \\
-0.469 \\
0.060 \\
-0.460 \\
-0.073 \\
0.240 \\
-0.039\end{array}$ \\
\hline $\mathrm{Cr}(\mathrm{BA})\left(\mathrm{OH}^{-}\right) \cdot 4 \mathrm{H}_{2} \mathrm{O}$ & $\begin{array}{l}241.32-290.61 \\
370.79-442.13\end{array}$ & $\begin{array}{l}276.42 \\
415.83\end{array}$ & $\begin{array}{l}-27.35 \\
-109.51\end{array}$ & $\begin{array}{l}-0.099 \\
-0.263\end{array}$ & $\begin{array}{l}0.015 \\
-0.105 \\
-0.447 \\
0.521 \\
0.017 \\
-0.562 \\
1.364 \\
0.104 \\
-0.308\end{array}$ & $\begin{array}{l}-24.095 \\
34.062 \\
214.790 \\
-320.860 \\
-36.773 \\
343.006 \\
-993.696 \\
-100.836 \\
215.479\end{array}$ & $\begin{array}{l}2 \times 10^{-7} \\
-1 \times 10^{-7} \\
-7 \times 10^{-7} \\
9 \times 10^{-7} \\
9 \times 10^{-8} \\
-6 \times 10^{-7} \\
1 \times 10^{-6} \\
1 \times 10^{-7} \\
-2 \times 10^{-7}\end{array}$ & $\begin{array}{l}-0.071 \\
-0.002 \\
0.148 \\
-0.341 \\
-0.075 \\
0.209 \\
0.770 \\
-0.102 \\
0.097\end{array}$ \\
\hline
\end{tabular}




\begin{tabular}{|c|c|c|c|c|c|c|c|c|}
\hline Compound & $\begin{array}{l}\text { Heat range } \\
{ }^{\circ} \mathrm{C}\end{array}$ & $\begin{array}{l}\mathbf{T}_{\mathbf{m}} \\
{ }^{\circ} \mathbf{C}\end{array}$ & $\begin{array}{l}\Delta \mathrm{H} \\
\mathrm{J} / \mathrm{g}\end{array}$ & $\begin{array}{l}\Delta S \\
\text { J/g. }{ }^{\circ} \mathrm{C}\end{array}$ & $\mathbf{a}$ & b & $\alpha$ & $\gamma$ \\
\hline $\mathrm{Zn}(\mathrm{BA})_{2} .3 \mathrm{H}_{2} \mathrm{O}$ & $\begin{array}{l}224.08-299.86 \\
336.64-432.18\end{array}$ & $\begin{array}{l}281.57 \\
391.37\end{array}$ & $\begin{array}{l}-360.77 \\
-165.68\end{array}$ & $\begin{array}{l}-1.281 \\
-0.423\end{array}$ & $\begin{array}{c}-0.052 \\
-1.517 \\
-1.930 \\
6.105 \\
-0.440 \\
0.478 \\
-0.187\end{array}$ & $\begin{array}{l}11.907 \\
752.913 \\
980.786 \\
-3495.263 \\
242.801 \\
-368.919 \\
103.030\end{array}$ & $\begin{array}{l}-6 \times 10^{-8} \\
-3 \times 10^{-6} \\
-2 \times 10^{-6} \\
1 \times 10^{-5} \\
-5 \times 10^{-7} \\
6 \times 10^{-7} \\
-1 \times 10^{-7}\end{array}$ & $\begin{array}{l}-0.011 \\
0.611 \\
0.600 \\
-3.601 \\
0.152 \\
-0.325 \\
0.007\end{array}$ \\
\hline $\mathrm{Cd}(\mathrm{BA})_{2 .} \cdot 10 \mathrm{H}_{2} \mathrm{O}$ & $\begin{array}{l}229.83-263.38 \\
263.87-287.04 \\
361.52-452.57\end{array}$ & $\begin{array}{l}256.73 \\
281.28 \\
422.48\end{array}$ & $\begin{array}{l}-98.96 \\
-45.93 \\
-378.43\end{array}$ & $\begin{array}{l}-0.385 \\
-0.163 \\
-0.896\end{array}$ & $\begin{array}{l}-0.059 \\
-0.448 \\
-4.669 \\
8.591 \\
-0.777 \\
3.333 \\
-0.335 \\
-1.726 \\
-0.256 \\
-4.506\end{array}$ & $\begin{array}{l}13.671 \\
200.431 \\
2397.860 \\
-4645.683 \\
388.046 \\
-1890.435 \\
177.283 \\
1110.455 \\
156.717 \\
3636.635\end{array}$ & $\begin{array}{l}-1 \times 10^{-7} \\
-4 \times 10^{-6} \\
2 \times 10^{-5} \\
-1 \times 10^{-6} \\
4 \times 10^{-6} \\
-3 \times 10^{-7} \\
-1 \times 10^{-6} \\
2 \times 10^{-6} \\
-2 \times 10^{-7} \\
-3 \times 10^{-6}\end{array}$ & $\begin{array}{l}-0.006 \\
1.101 \\
-4.437 \\
0.375 \\
-1.371 \\
0.066 \\
0.508 \\
-1.331 \\
0.084 \\
1.934\end{array}$ \\
\hline $\mathrm{Hg}(\mathrm{BA})_{2}$ & $\begin{array}{l}211.53-278.74 \\
344.83-460.24\end{array}$ & $\begin{array}{l}248.49 \\
418.24\end{array}$ & $\begin{array}{l}-118.14 \\
-278.52\end{array}$ & $\begin{array}{l}-0.475 \\
-0.666\end{array}$ & $\begin{array}{l}-0.193 \\
-0.814 \\
1.610 \\
-0.316 \\
-1.184 \\
1.678 \\
0.135 \\
-0.464\end{array}$ & $\begin{array}{l}61.372 \\
366.447 \\
-907.689 \\
154.413 \\
722.833 \\
-1259.549 \\
-143.903 \\
335.441\end{array}$ & $\begin{array}{l}-3 \times 10^{-7} \\
2 \times 10^{-6} \\
2 \times 10^{-6} \\
-4 \times 10^{-7} \\
-1 \times 10^{-6} \\
2 \times 10^{-6} \\
2 \times 10^{-7} \\
-3 \times 10^{-7}\end{array}$ & $\begin{array}{l}-0.001 \\
0.363 \\
-0.560 \\
0.071 \\
0.464 \\
-0.980 \\
-0.147 \\
0.151\end{array}$ \\
\hline
\end{tabular}

\begin{tabular}{|c|c|c|c|c|c|c|c|c|}
\hline Compound & $\begin{array}{l}\text { Heat range } \\
{ }^{\circ} \mathrm{C}\end{array}$ & $\begin{array}{l}\mathbf{T}_{\mathrm{m}} \\
{ }^{\circ} \mathrm{C}\end{array}$ & $\begin{array}{l}\Delta \mathrm{H} \\
\mathrm{J} / \mathrm{g}\end{array}$ & $\begin{array}{l}\Delta S \\
\text { J/g. }{ }^{\circ} \mathrm{C}\end{array}$ & $\mathbf{a}$ & b & $\alpha$ & $\gamma$ \\
\hline $\mathrm{Fe}(\mathrm{TBA})\left(\mathrm{OH}^{-}\right) .2 \mathrm{H}_{2} \mathrm{O}$ & $\begin{array}{l}30.77-131.67 \\
131.67-310.00\end{array}$ & $\begin{array}{l}91.41 \\
250.66\end{array}$ & $\begin{array}{l}-99.61 \\
-189.19\end{array}$ & $\begin{array}{l}-1.090 \\
-0.755\end{array}$ & $\begin{array}{l}-1.185 \\
-0.163 \\
0.152 \\
-0.160 \\
0.019 \\
-0.168 \\
0.202 \\
0.042 \\
1.214 \\
-1.358 \\
-0.158\end{array}$ & $\begin{array}{l}350.707 \\
27.568 \\
-88.976 \\
39.768 \\
-42.363 \\
59.401 \\
-145.415 \\
-51.158 \\
-833.564 \\
935.700 \\
92.528\end{array}$ & $\begin{array}{l}-2 \times 10^{-5} \\
-5 \times 10^{-7} \\
7 \times 10^{-7} \\
-3 \times 10^{-7} \\
2 \times 10^{-7} \\
-2 \times 10^{-7} \\
5 \times 10^{-7} \\
1 \times 10^{-7} \\
1 \times 10^{-6} \\
-1 \times 10^{-6} \\
-1 \times 10^{-7}\end{array}$ & $\begin{array}{l}2.025 \\
-0.028 \\
-0.176 \\
-0.005 \\
-0.113 \\
-0.012 \\
-0.202 \\
-0.077 \\
-0.548 \\
0.653 \\
0.028\end{array}$ \\
\hline $\mathrm{Cr}(\mathrm{TU})\left(\mathrm{OH}^{-}\right)_{2} \cdot \mathrm{H}_{2} \mathrm{O}$ & $\begin{array}{l}30.91-228.57 \\
228.57-491.57\end{array}$ & $\begin{array}{l}105.57 \\
319.98\end{array}$ & $\begin{array}{l}-445.27 \\
-480.27\end{array}$ & $\begin{array}{l}-4.218 \\
-1.501\end{array}$ & $\begin{array}{l}-7.545 \\
-0.346\end{array}$ & $\begin{array}{l}2296.701 \\
87.023\end{array}$ & $\begin{array}{l}-4 \times 10^{-5} \\
-9 \times 10^{-7}\end{array}$ & $\begin{array}{l}3.712 \\
0.019\end{array}$ \\
\hline
\end{tabular}




\begin{tabular}{|c|c|c|c|c|c|c|c|c|}
\hline & & & & & $\begin{array}{l}0.145 \\
0.351 \\
-0.504 \\
-118 \\
0.080 \\
0.069 \\
-0.109 \\
0.170\end{array}$ & $\begin{array}{l}-100.927 \\
-198.127 \\
238.445 \\
24.684 \\
-94.083 \\
-86.838 \\
49.972 \\
-169.707\end{array}$ & $\begin{array}{l}8 \times 10^{-7} \\
7 \times 10^{-7} \\
-8 \times 10^{-7} \\
-6 \times 10^{-8} \\
2 \times 10^{-7} \\
1 \times 10^{-7} \\
-2 \times 10^{-8} \\
2 \times 10^{-7}\end{array}$ & $\begin{array}{l}-0.241 \\
-0.217 \\
0.176 \\
-0.054 \\
-0.150 \\
-0.108 \\
-0.031 \\
-0.141\end{array}$ \\
\hline $\mathrm{Hg}(\mathrm{TU})_{2 .} 4 \mathrm{H}_{2} \mathrm{O}$ & $217.68-286.05$ & 274.62 & -710.87 & -2.589 & $\begin{array}{l}-0.034 \\
-2.422 \\
7.158 \\
0.123 \\
-0.630 \\
-4.438\end{array}$ & $\begin{array}{l}-2.563 \\
1284 \\
-4036.643 \\
-83.801 \\
388.615 \\
3382.770\end{array}$ & $\begin{array}{l}1 \times 10^{-7} \\
-2 \times 10^{-7} \\
-4 \times 10^{-6} \\
1 \times 10^{-5} \\
2 \times 10^{-7} \\
-6 \times 10^{-7} \\
-3 \times 10^{-6}\end{array}$ & $\begin{array}{l}-0.058 \\
0.011 \\
1.085 \\
-3.562 \\
-0.088 \\
0.228 \\
1.582\end{array}$ \\
\hline
\end{tabular}

* All are of exothermic behavior.

All the complexes gave exothermic peaks. All the change of entropy values, $\Delta \mathrm{S}$ have -ve signs which indicate that the activated transition states are more ordered, i.e. in a less random molecular configuration than the reacting complexes [25-30].

The decomposition pattern may be affected by stereochemistry of the metal complex and in some cases with the electronic character [31].

From TGA, Figures (21-27) Table (3) the mechanism of decomposition can be given.

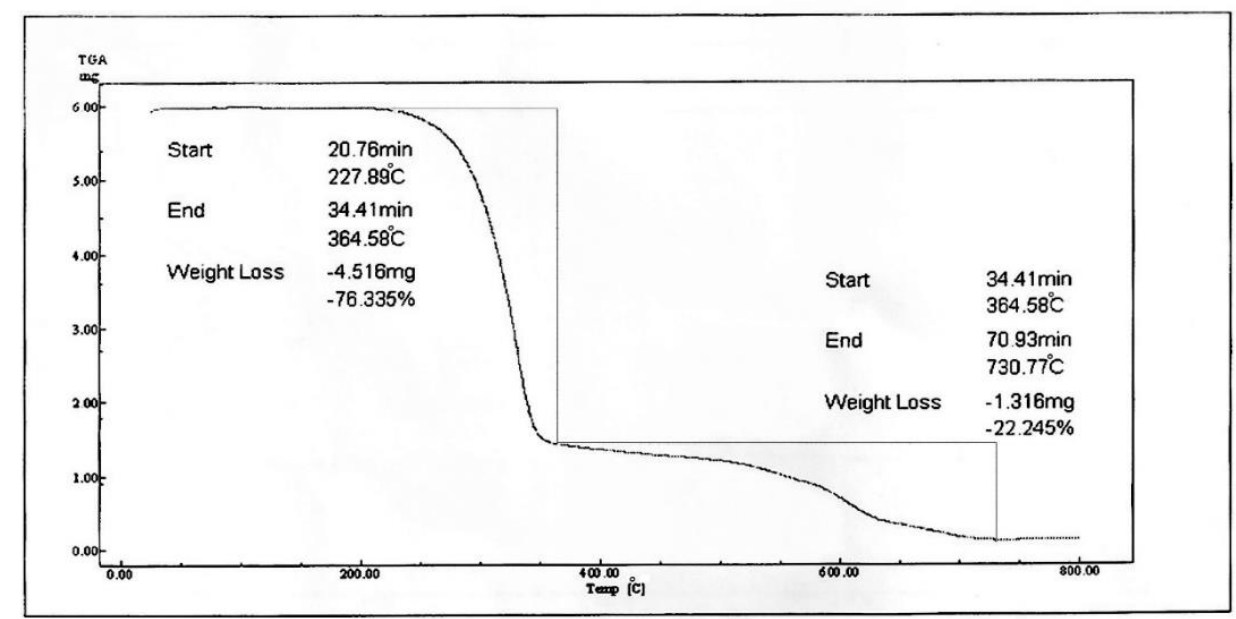

Figure 21 TGA for Hydroxyethyladenine. 
World Journal of Advanced Research and Reviews, 2021, 12(02), 078-108

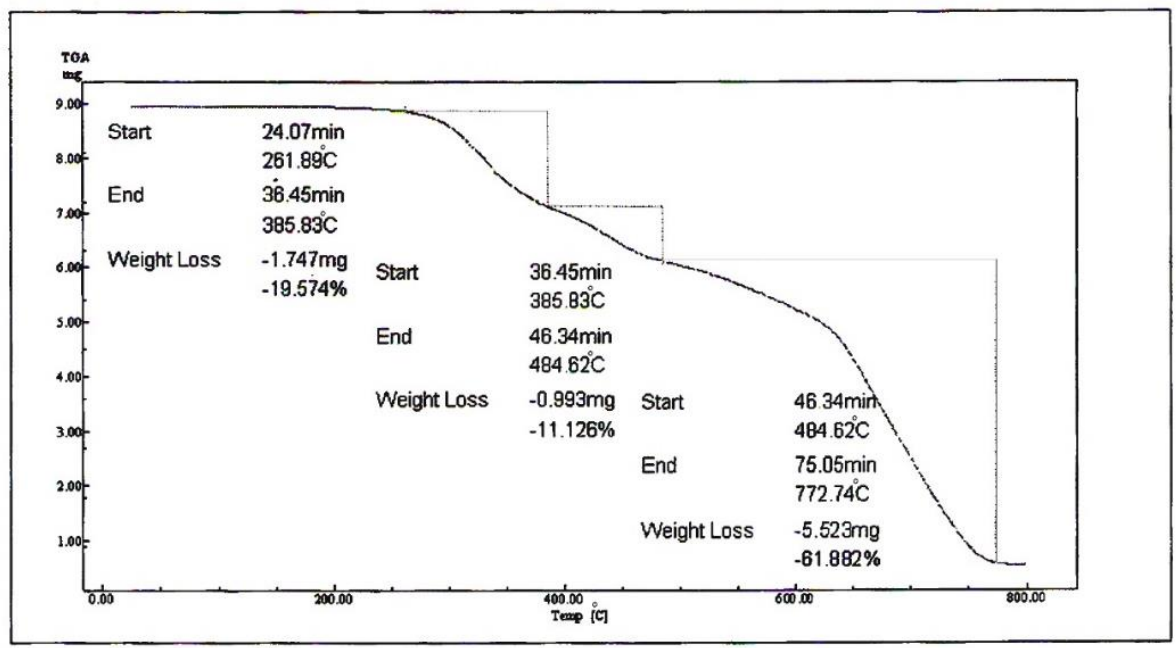

Figure $22 \mathrm{TGA}$ for $\mathrm{Zn}$ (hydroxyethyladenine) $2\left(\mathrm{OH}^{-}\right)_{2} .2 \mathrm{H}_{2} \mathrm{O}$.

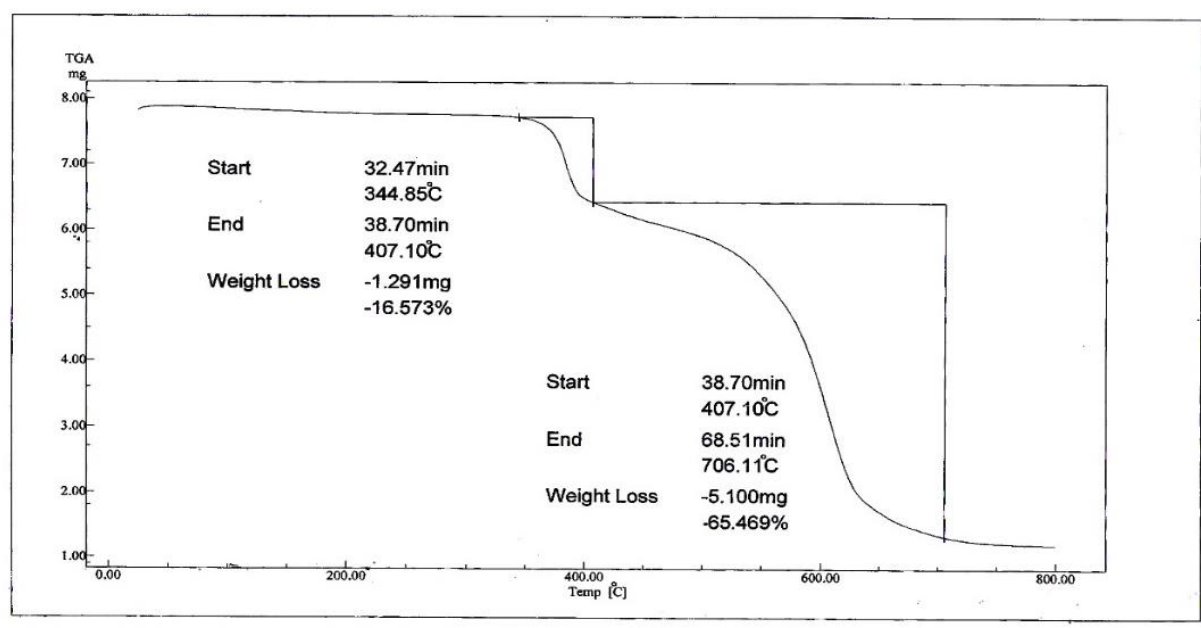

Figure 23 TGA for Cd (hydroxyethyladenine) $\left(\mathrm{OH}^{-}\right)_{2} .3 \mathrm{H}_{2} \mathrm{O}$.

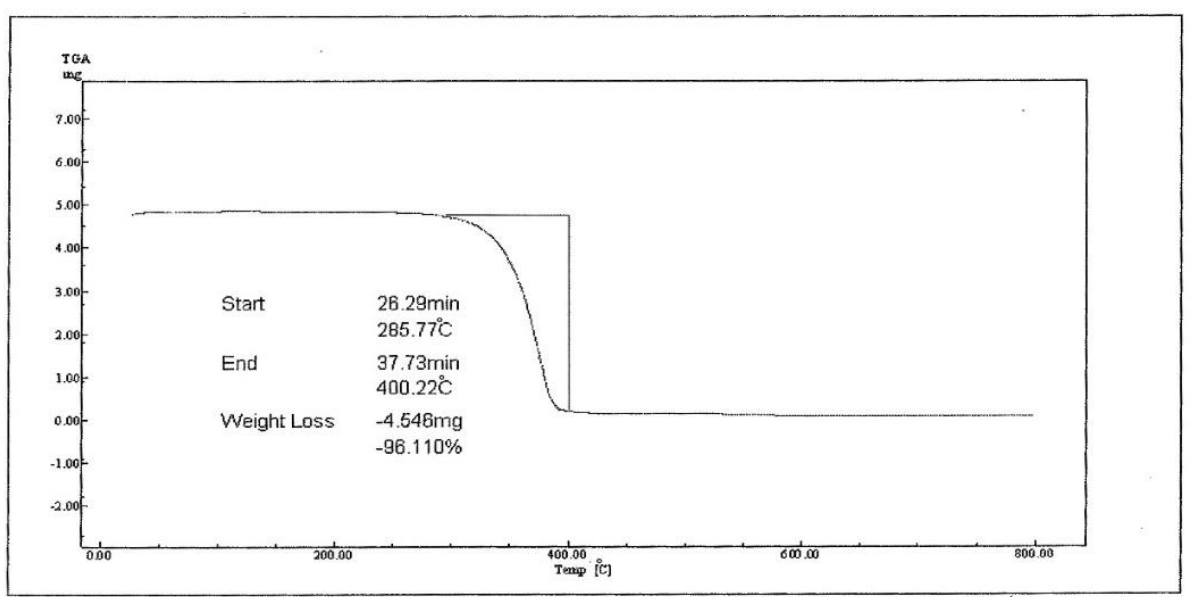

Figure 24 TGA for Acetyladenine. 


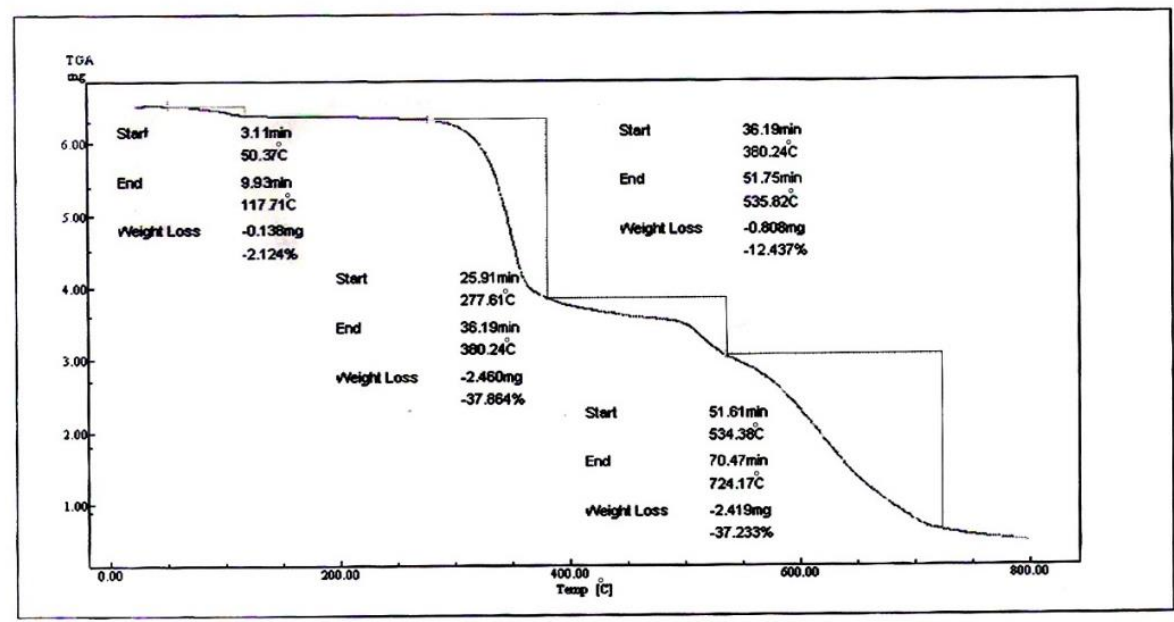

Figure 25 TGA for Cd (II) ( ${ }^{6} \mathrm{~N}$-acetyladenine $)_{2}\left(\mathrm{OH}^{-}\right)_{2} .2 \mathrm{H}_{2} \mathrm{O}$.

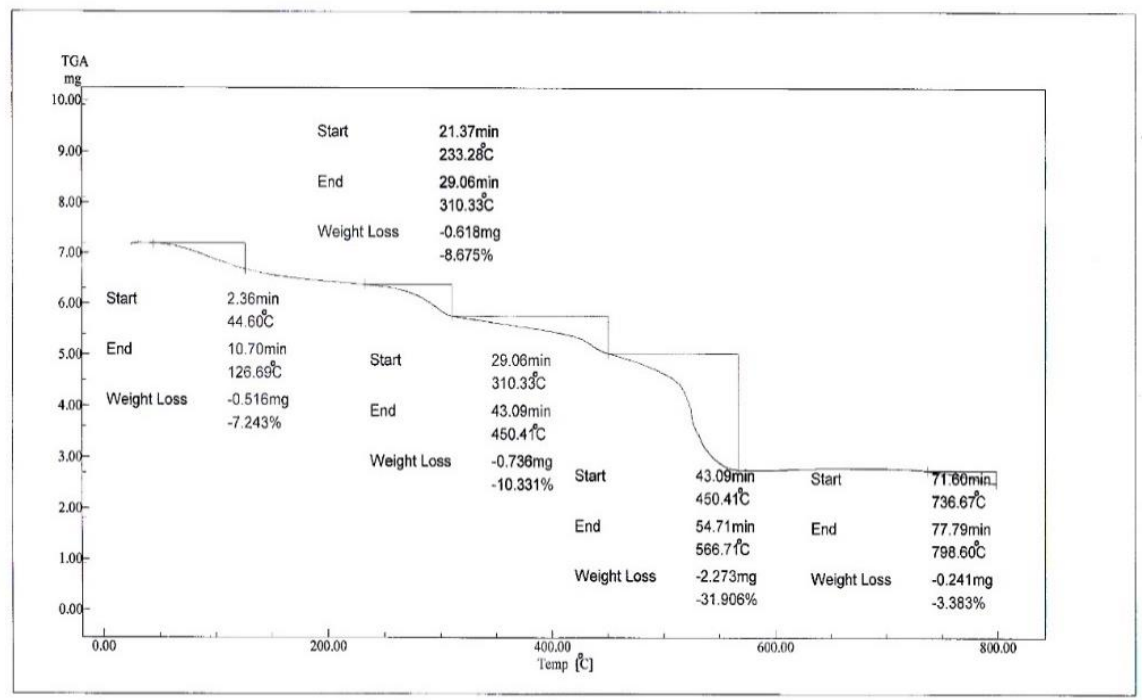

Figure $26 \mathrm{TGA}$ for $\mathrm{Co}-\mathrm{Ni}(\mathrm{TU})_{3} .4 \mathrm{H}_{2} \mathrm{O}$.

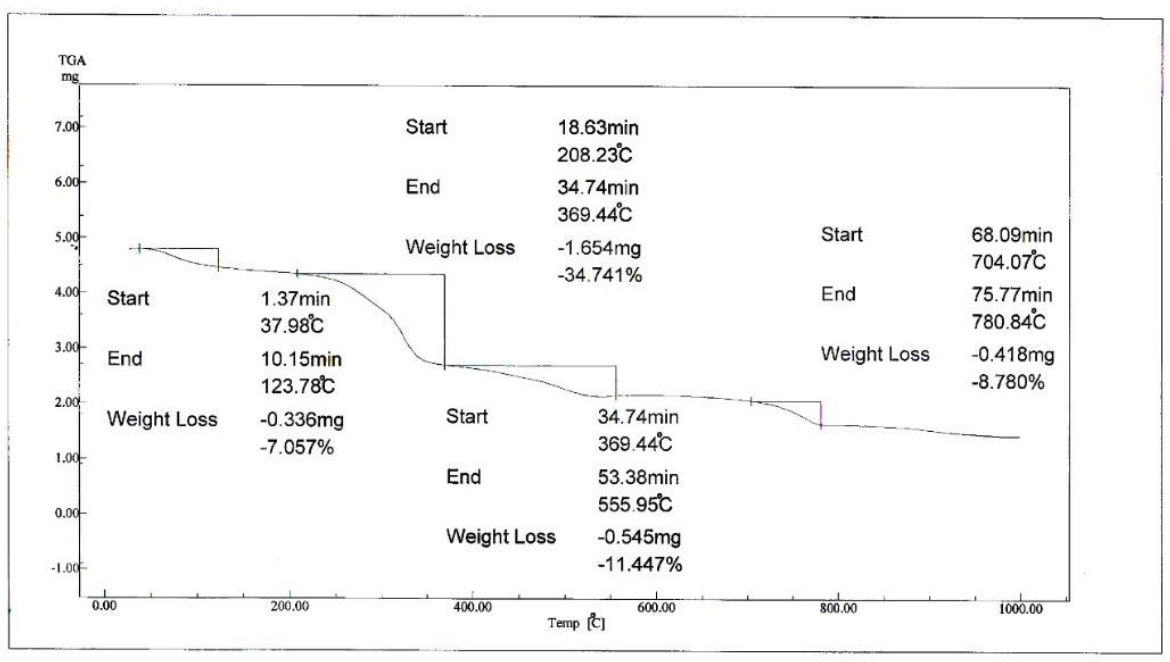

Figure $27 \mathrm{TGA}$ for $\mathrm{Ni}-\mathrm{Cu}(\mathrm{TU})_{3} .4 \mathrm{H}_{2} \mathrm{O}$. 
Table 3 TGA analyses of some compounds.

\begin{tabular}{|c|c|c|c|}
\hline Compound & $\begin{array}{l}\text { Weight loss \% } \\
\text { (calculated) }\end{array}$ & $\begin{array}{l}\text { Weight loss \% } \\
\text { (found) }\end{array}$ & Assignments \\
\hline Hydroxyethyladenine & $\begin{array}{l}77.65 \\
22.35\end{array}$ & $\begin{array}{l}76.34 \\
22.25\end{array}$ & $\begin{array}{l}\mathrm{C}_{2} \mathrm{H}_{4} \mathrm{OH}, \mathrm{C}_{3} \mathrm{H}_{2} \mathrm{~N}_{4} \\
\mathrm{C}_{2} \mathrm{H}_{2} \mathrm{~N}\end{array}$ \\
\hline $\mathrm{Zn}$ (hydroxyethyladenine) $)_{2}\left(\mathrm{OH}^{-}\right)_{2} \cdot 2 \mathrm{H}_{2} \mathrm{O}$ & $\begin{array}{l}19.87 \\
12.57 \\
60.95\end{array}$ & $\begin{array}{l}19.57 \\
11.13 \\
61.88\end{array}$ & $\begin{array}{l}2 \mathrm{H}_{2} \mathrm{O}, \mathrm{OH}-, \mathrm{C}_{2} \mathrm{H}_{4} \mathrm{OH} \\
\mathrm{OH}^{-}, \mathrm{C}_{2} \mathrm{H}_{4} \mathrm{OH} \\
\mathrm{C}_{10} \mathrm{H}_{8} \mathrm{~N}_{10}, 0.5 \mathrm{Zn} \\
\text { Remains: } 0.5 \mathrm{Zn}\end{array}$ \\
\hline Cd (hydroxyethyladenine) $\left(\mathrm{OH}^{-}\right)_{2} .3 \mathrm{H}_{2} \mathrm{O}$ & $\begin{array}{l}18.72 \\
66.48\end{array}$ & $\begin{array}{l}16.57 \\
65.47\end{array}$ & $\begin{array}{l}3 \mathrm{H}_{2} \mathrm{O}, \mathrm{OH}^{-} \\
\mathrm{OH}^{-}, \mathrm{C}_{2} \mathrm{H}_{4} \mathrm{OH}, \mathrm{C}_{5} \mathrm{H}_{4} \mathrm{~N}_{5}, 0.5 \mathrm{Cd} \\
\text { Remains: } 0.5 \mathrm{Cd}\end{array}$ \\
\hline Acetyladenine & 100 & 96.11 & $\mathrm{C}_{7} \mathrm{H}_{7} \mathrm{~N}_{5} \mathrm{O}$ \\
\hline $\mathrm{Cd}$ (acetyladenine) $)_{2}\left(\mathrm{OH}^{-}\right)_{2} .2 \mathrm{H}_{2} \mathrm{O}$ & $\begin{array}{l}3.36 \\
37.66 \\
38.04 \\
10.47\end{array}$ & $\begin{array}{l}2.12 \\
37.86 \\
37.23 \\
12.44\end{array}$ & $\begin{array}{l}\mathrm{H}_{2} \mathrm{O} \\
\mathrm{H}_{2} \mathrm{O}, 2\left(\mathrm{OH}^{-}\right), \mathrm{C}_{6} \mathrm{H}_{6} \mathrm{~N}_{4} \mathrm{O} \\
\mathrm{C}_{8} \mathrm{H}_{8} \mathrm{~N}_{6} \mathrm{O} \\
0.5 \mathrm{Cd} \\
\text { Remains: } 0.5 \mathrm{Cd}\end{array}$ \\
\hline Co-Ni $(\mathrm{TU})_{3} .4 \mathrm{H}_{2} \mathrm{O}$ & $\begin{array}{l}6.32 \\
9.30 \\
10.19 \\
31.43 \\
4.57\end{array}$ & $\begin{array}{l}7.24 \\
8.68 \\
10.33 \\
31.91 \\
3.38\end{array}$ & $\begin{array}{l}2 \mathrm{H}_{2} \mathrm{O} \\
2 \mathrm{H}_{2} \mathrm{O}, \mathrm{OH} \\
\mathrm{CNS} \\
\mathrm{C}_{4} \mathrm{H}_{3} \mathrm{~N}_{2} \mathrm{OS}, \mathrm{C}_{3} \mathrm{H}_{2} \mathrm{~N} \\
\mathrm{C}_{2} \mathrm{H}_{2} \\
\text { Remains: } \mathrm{C}_{2} \mathrm{~N}_{2} \mathrm{OSCoNi}\end{array}$ \\
\hline $\mathrm{Ni}-\mathrm{Cu}(\mathrm{TU})_{3 .} 4 \mathrm{H}_{2} \mathrm{O}$ & $\begin{array}{l}6.27 \\
35.88 \\
12.20 \\
9.06\end{array}$ & $\begin{array}{l}7.06 \\
34.74 \\
11.45 \\
8.78\end{array}$ & $\begin{array}{l}2 \mathrm{H}_{2} \mathrm{O} \\
2 \mathrm{H}_{2} \mathrm{O}, \mathrm{OH}, \mathrm{C}_{2} \mathrm{H}_{2}, \mathrm{C}_{4} \mathrm{H}_{3} \mathrm{~N}_{2} \mathrm{OS} \\
\mathrm{C}_{2} \mathrm{NS} \\
\mathrm{C}_{2} \mathrm{H}_{2} \mathrm{~N} \\
\text { Remains: } \mathrm{CN}_{2} \mathrm{OSNiCu}\end{array}$ \\
\hline
\end{tabular}

The fragmentation pathways of the compounds can be represented as follows: 


\section{1-Hydroxyethyladenine}

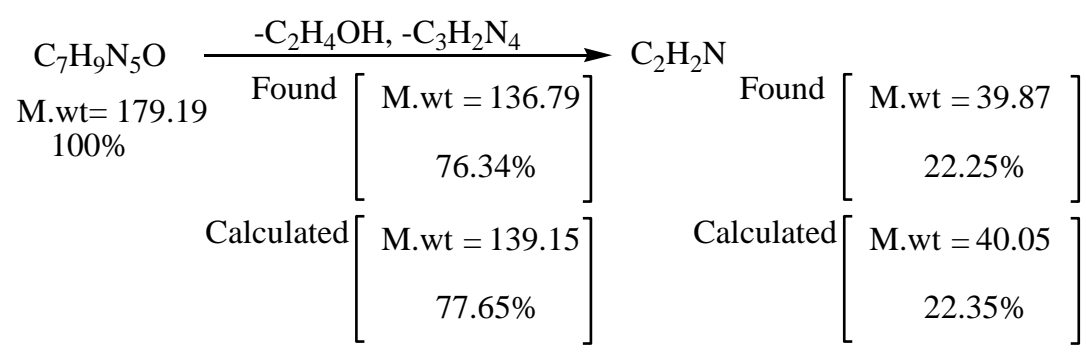

\section{$2-\mathrm{Zn}(\text { hydroxyethyladenine })_{2}\left(\mathrm{OH}^{-}\right)_{2} \cdot 2 \mathrm{H}_{2} \mathrm{O}$}

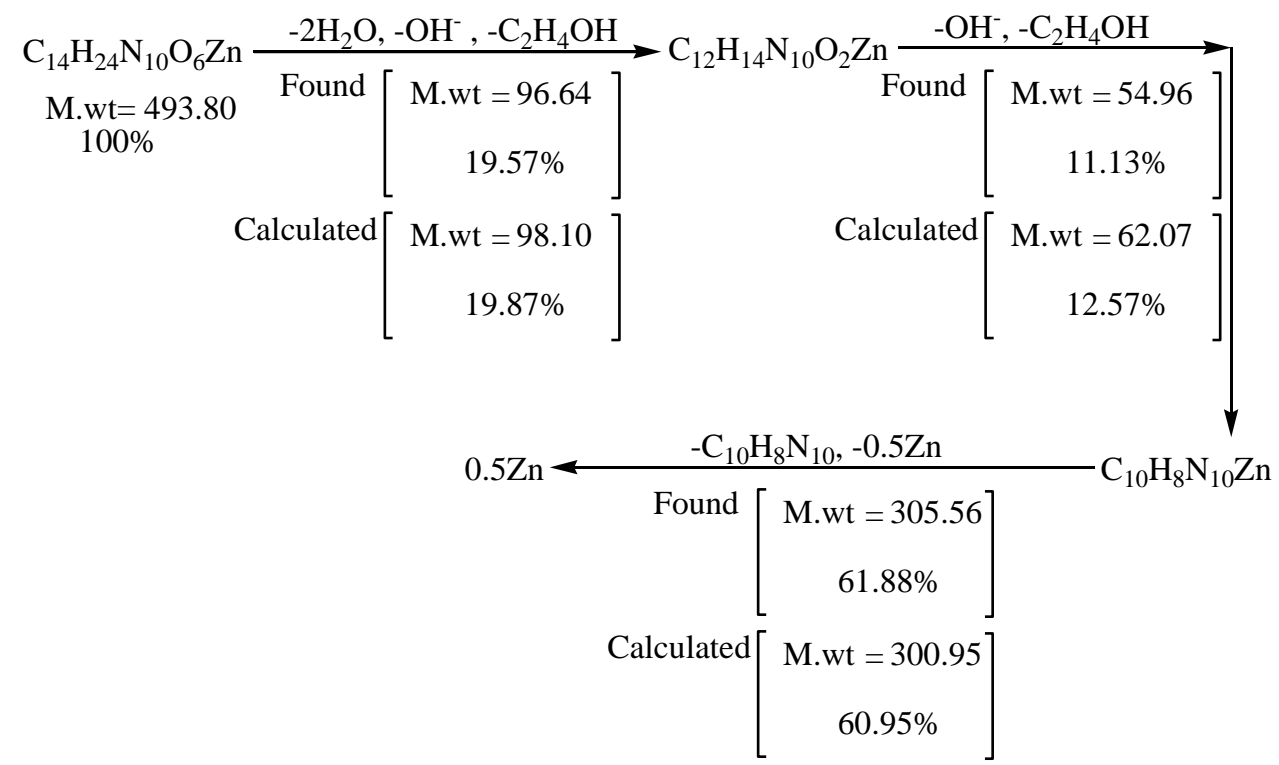

3-Cd(hydroxyethyladenine $)\left(\mathrm{OH}^{-}\right)_{2} \cdot 3 \mathrm{H}_{2} \mathrm{O}$

\begin{tabular}{|c|c|c|c|c|}
\hline \multirow{2}{*}{$\begin{array}{c}\mathrm{C}_{7} \mathrm{H}_{17} \mathrm{~N}_{5} \mathrm{O}_{6} \mathrm{Cd} \\
\mathrm{M} . \mathrm{wt}=379.66 \\
100 \%\end{array}$} & \multicolumn{2}{|c|}{$-3 \mathrm{H}_{2} \mathrm{O},-\mathrm{OH}^{-}$} & \multicolumn{2}{|c|}{$-\mathrm{OH}^{-},-\mathrm{C}_{2} \mathrm{H}_{4} \mathrm{OH}$} \\
\hline & Found & $\begin{array}{c}\text { M.wt }=62.91 \\
16.57 \%\end{array}$ & Found & $\begin{array}{c}\text { M.wt }=248.56 \\
65.47 \%\end{array}$ \\
\hline & alculated & $\begin{array}{c}\text { M.wt }=71.06 \\
18.72 \%\end{array}$ & Calculated & $\begin{array}{c}\text { M.wt }=252.40 \\
66.48 \%\end{array}$ \\
\hline
\end{tabular}




\section{4-Cd(acetyladenine $)_{2}\left(\mathrm{OH}^{-}\right)_{2} \cdot 2 \mathrm{H}_{2} \mathrm{O}$}

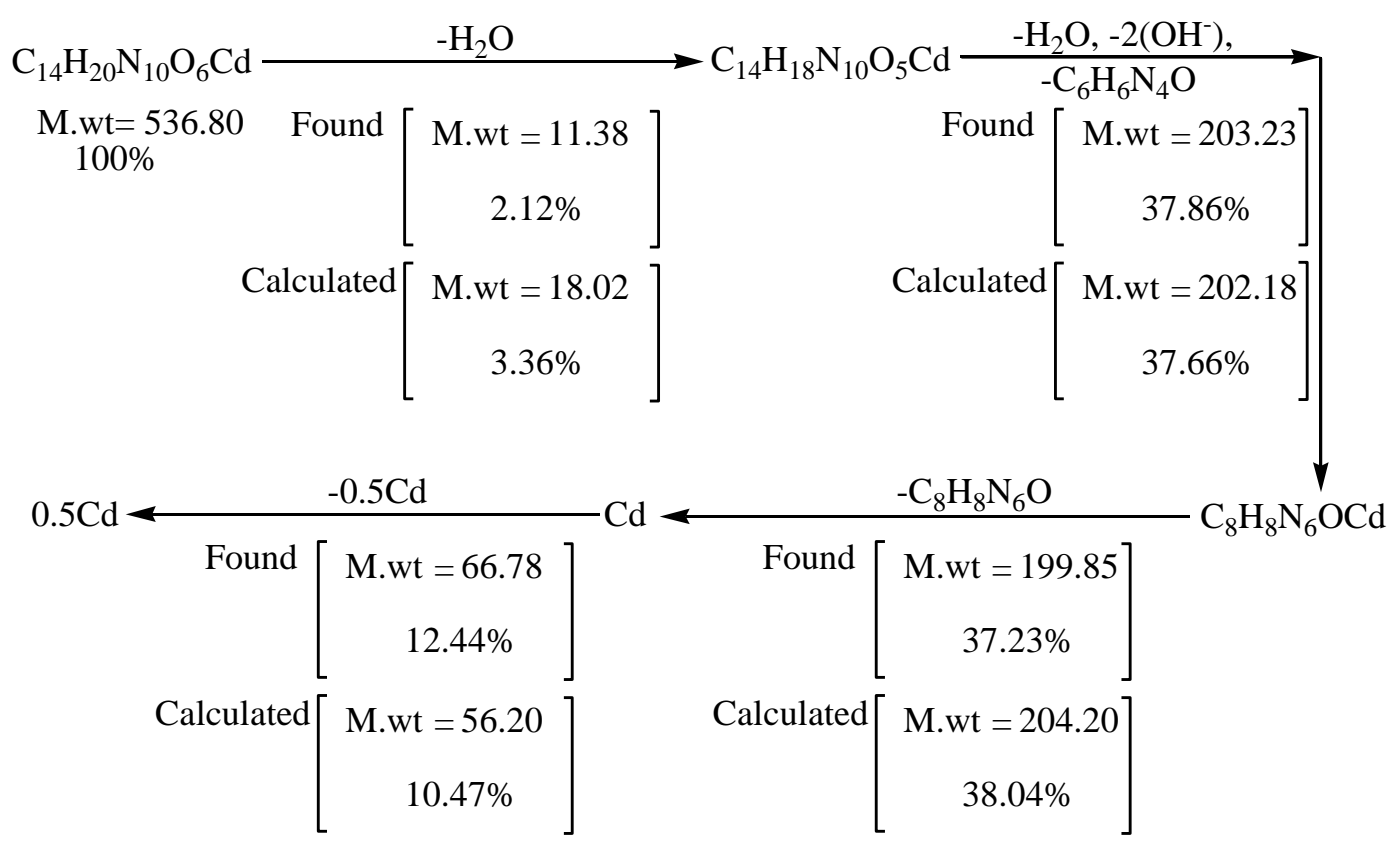

5-Co-Ni(TU) $)_{3} \cdot \mathbf{H H}_{2} \mathrm{O}$
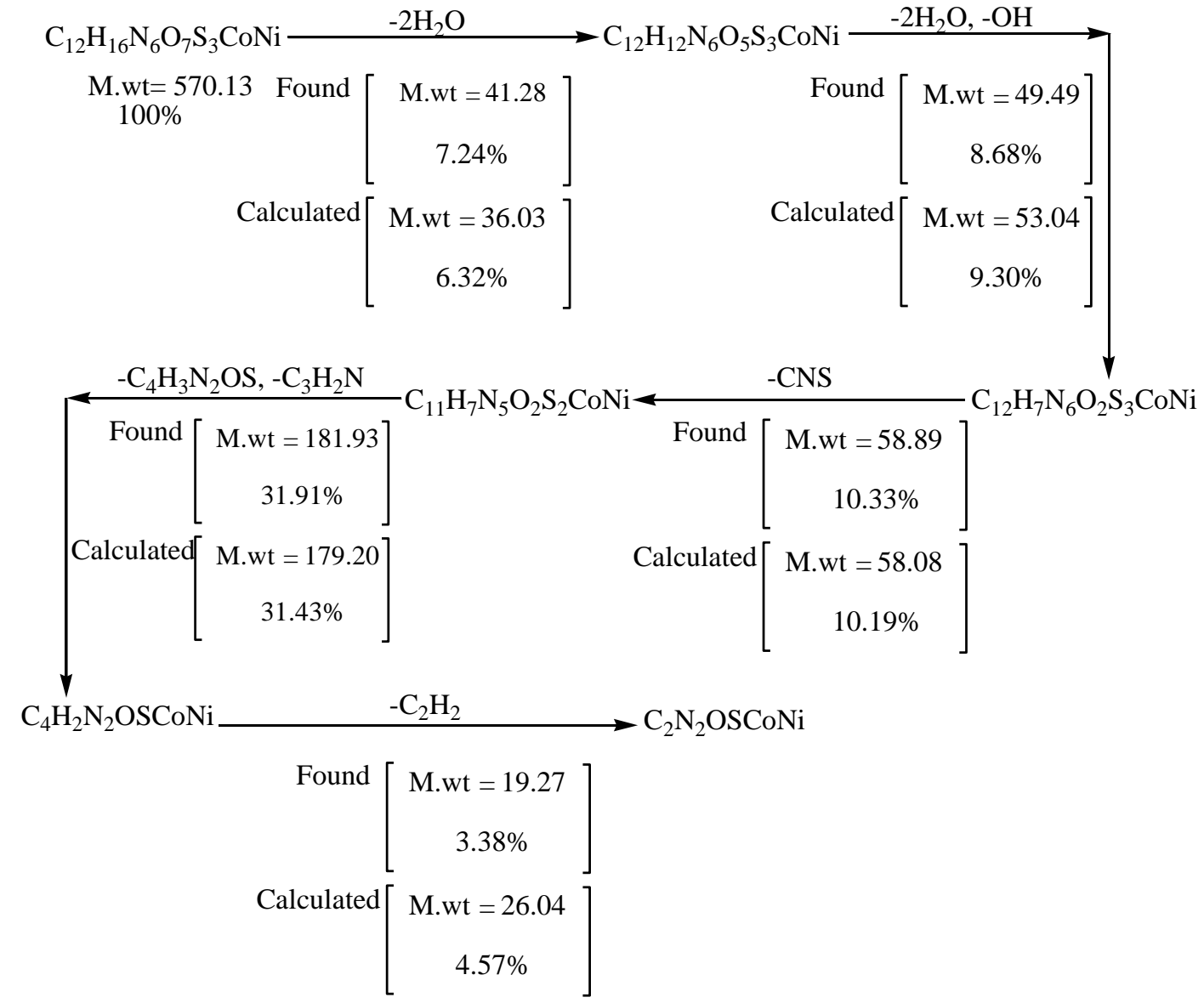
6-Ni-Cu(TU) ${ }_{3} \cdot 4 \mathrm{H}_{2} \mathrm{O}$

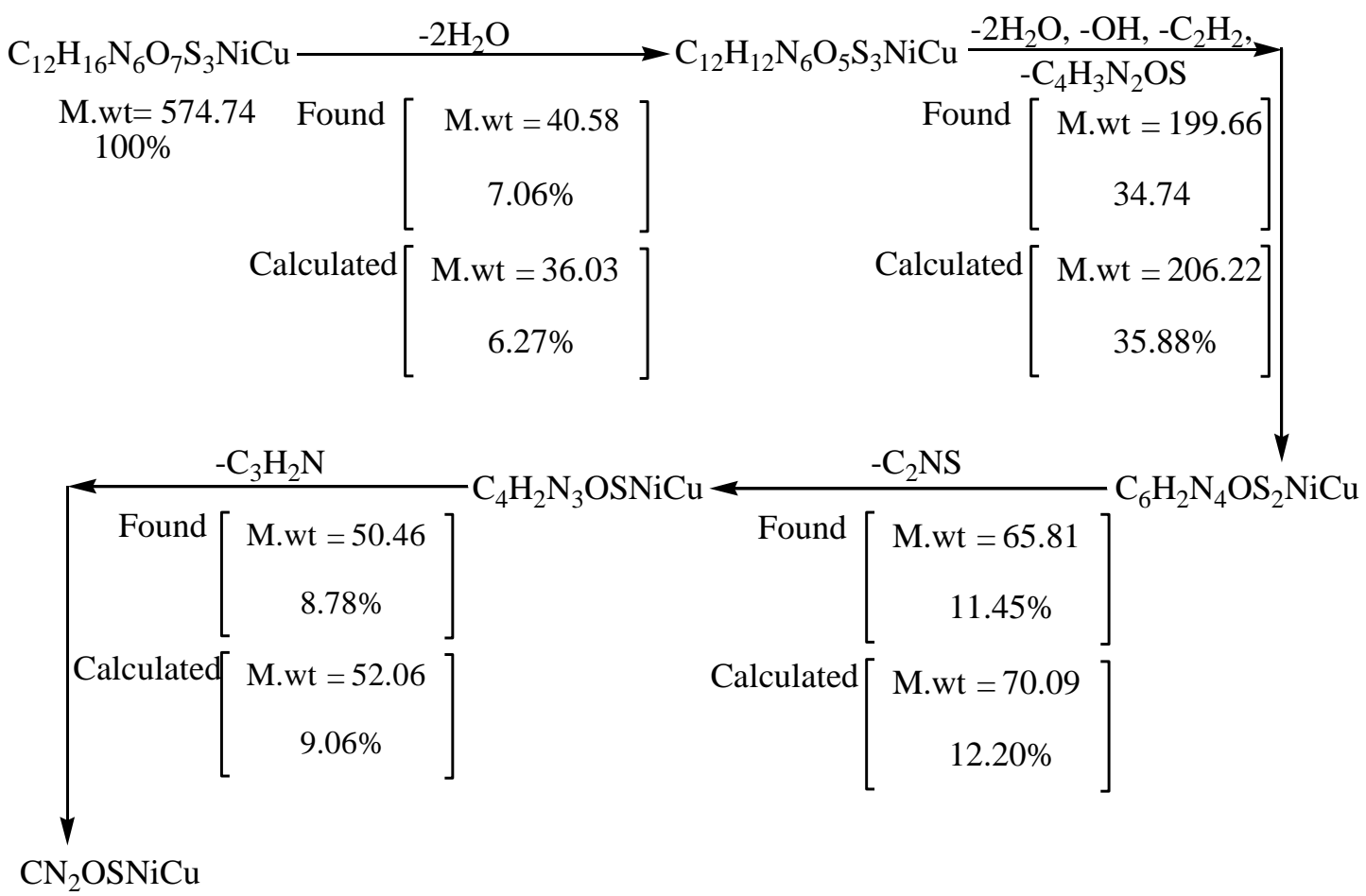

\section{Conclusion}

DSC and TGA of some nucleic acid compounds are given. The mechanism of thermodynamic parameters is explained.

\section{Compliance with ethical standards}

\section{Acknowledgments}

We would like to thank our committee for providing chemicals and all the facilities for measuring the data.

\section{Disclosure of conflict of interest}

All the authors are satisfied to the data.

\section{References}

[1] K. J. Barnham, M. I. Djuran, P. S. Murdoch and P. J. Sadler, J. Chem. Soc. Chem. Commun. 1994 ;721.

[2] K. J. Barnham, M. I. Djuran, P.S. Murdoch, J. D. Ranford and P. J. Sadler, J. Chem. Soc. Dalton Trans. 1995: 3721; Inorg. Chem., 1996; 35:1065.

[3] A. Vogel, "Textbook of Quantitative Chemical Analysis", 4th Indian Reprint 2004.

[4] C. Duval, Inorganic and Thermogravimetric Analysis, Elsevier, Amsterdam 1953.

[5] W. W. Wendlandt, Anal. Chem., 1955; 27:1277; Anal. Chim. Acta 1956; 15:109; 1957; 17:274.

[6] W. W. Wendlandt and I. M. Bryant. The thermolysis of the neocupferron chelates of yttrium and the rare earth elements. Anal. Chim. Acta 1955; 13, 550.

[7] G. De, P. K. Biswas and N. R. Chaudhuri, J. Chem. Soc. Dalton trans., 1984; 259.

[8] J. R. Lusty, H. S. Chan, E. Khar and J. Pecling, Inorg. Chim. Acta, 1985; 106: 209.

[9] K. Miyokawa and I. Masuda, J. Phys. Chem. Solids, 1986; 47, 13.

[10] A. Ghosh, G. De and N. R. Chaudhuri, J. Chem. Res., 1987; 1:104. 
[11] L. Deuschle and U. Weser, Inorg. Chim. Acta, 1987; 135:5.

[12] A. M. Donia and E. M. Ebeid, Thermochim. Acta, 1988; 131:1.

[13] S. R. Byrn, Solid State Chemistry of Drugs, Acad. Press, N Y, London 1982.

[14] M. S. Masoud, E. A. Khalil, E. El-Sayed El-Shereafy and S. A. El-Enein. Thermal and electrical behaviour of nickel (II) and copper (II) complexes of 4-acetamidophenylazo-p-cresol (4-acetylamino-2-hydroxy-5-methyl azobenzene). J. Therm. Anal., 1990; 36:1033.

[15] M. S. Masoud, A. M. Ramadan and Gh. M El-Ashry. Thermal Properties of Some Pyrimidines, Purines, Amino Acid and Mixed Ligand Complexes. Thermochim. Acta, 2013; 551, 164.

[16] G. E. Pike, Phys. Rev., 1972; B6, 1572; Philos B. Mag., 1972; 6:1582.

[17] S. R. Elliott, Philos. Mag., 1977; 36:1291.

[18] S. S. Kim and W. J. Kim, J. Crystal Growth, 2005; 281 (2-4):432.

[19] P. S. Anantha and K. Hariharan, J. Materials Science and Engineering B, 2005; 121 (1-2):12.

[20] H. M. Zaki, J. Physica B Condensed Matter, 2005; 363 (1-4):232.

[21] M. Okutan, E. Basaran, H. I. Bakan and F. Yakuphanoglu, J. Physica B: Condensed Matter, 2005 ; 364 (1-4), 300.

[22] A. A. Hendi, Aust. J. Basic\& Appl. Sci., 2011; 5 (7)380.

[23] M. S. Masoud, A. E Ali and M. Y Abd El-Kaway. Thermal properties of mercury (II) and palladium (II) purine and pyrimidine complexes. J. Therm. Anal. Calorim., 2014 ; 116 (1):183.

[24] W. Brütting, Phys. Stat. Solidi A, 2004; 201:1035.

[25] M. S. Masoud, T. S. Kasem, M. A. Shaker and A. A. Ali. Studies on Transition Metal Murexide Complexes. J. Therm. Anal. Calorim., 2006; 84 (3):549.

[26] M. S. Masoud, S. A. Abou El-Enein and A. M. Ramadan and A. S. Goher. Thermal properties of some biologically active 5- (p-substituted phenylazo)-6-aminouracil complexes. J. Anal. Appl. pyrolysis, 2008; 81 (1):45.

[27] M. S. Masoud, A. El-Merghany, A. M. Ramadan and M. Y. Abd El-Kaway, Thermal Studies of Some Purine Compounds and Their Metal Complexes. J. Therm. Anal. Calorim., 2010; 101 (3):839.

[28] M. S. Masoud, A. A. Soayed and A. F. El-Husseiny. Coordination Modes, Spectral, Thermal and Biological Evaluation of Hetero-Metal Copper Containing 2-Thio Uracil Complexes. Spectrochim. Acta, 2012; 99A:365.

[29] J. S. Blakemore, "Solid State Physics", 2nd Ed., Cambridge Univ. Press 1995.

[30] H. M. Rosenberg, "The Solid State", $3^{\text {rd }}$ Ed., Oxford Univ. Press 1997.

[31] M. S. Masoud, G. B. Mohamed, Y. H. Abdul-Razek, A. E. Ali and F. N. Khairy . Spectral, Magnetic and Thermal Properties of Some Thiazolylazo Complexes.J. Kor. Chem. Soc., 2002; 46 (2):99; Studies on Some Thiazolylazo Compounds and Their Cobalt, Nickel and Copper Complexes. Spectrosc. Lett., 2002;35:377. 